\title{
Preventing Nugget Shifting in Joining of Dissimilar Steels via Resistance Element Welding: A Numerical Simulation.
}

\section{Zhenghua Rao}

Central South University

Lei Liu

Central South University

\section{Yaqiong Wang}

Central South University

\section{Liang $\mathrm{Ou}$}

Central South University

Jiangwei Liu ( $\nabla$ jiangweiliu@csu.edu.cn )

Central South University

\section{Research Article}

Keywords: Resistance element welding, thermal contact behaviors, nugget development, heat generation, high strength steel

Posted Date: February 9th, 2021

DOl: https://doi.org/10.21203/rs.3.rs-178590/v1

License: (9) (1) This work is licensed under a Creative Commons Attribution 4.0 International License. Read Full License

Version of Record: A version of this preprint was published at The International Journal of Advanced Manufacturing Technology on July 28th, 2021. See the published version at https://doi.org/10.1007/s00170-021-07683-2. 


\title{
Preventing nugget shifting in joining of dissimilar steels via resistance element welding: a numerical simulation
}

\author{
Zhenghua Rao, Lei Liu, Yaqiong Wang, Liang Ou, Jiangwei Liu* \\ School of Energy Science and Engineering, Central South University, Changsha Hunan \\ 410083, China
}

\begin{abstract}
Joining the advanced high strength steels and the conventional steels is a critical issue for the manufacturing of lightweight vehicles. Resistance element welding (REW) is an emerging joining method for dissimilar metals and alloys by applying an auxiliary rivetlike resistance element in resistance spot welding (RSW). In this study, an electricalthermal-mechanical coupled REW model for high-strength dual-phase (DP) steel and Q235 steel was developed by considering contact resistances as functions of temperature and surface contacting area. The results show that the welding element in REW serves to concentrate the current flow and thus Joule heat generation at the faying interface between the element and workpiece. For welding DP600 and Q235 workpieces with a small thickness ratio $(\leq 0.4)$ or a high electrical resistivity ratio $(\geq 3)$, REW could effectively mitigate nugget shifting between workpieces and reducing the thermal excursion to electrode as compared to RSW. Adding well-designed insulation layers in REW could further concentrate the current within the welding element, and enables a large-sized nugget at a lower current. This study is significant because it provides a better understanding to the electrical-thermal-mechanical behaviors with interfacial contacts in REW and contributes to its further advance.
\end{abstract}

Keywords: Resistance element welding; thermal contact behaviors; nugget development; heat generation; high strength steel

\section{Acknowledgments}

This work was supported by Hunan Provincial Natural Science Foundation of China (2020JJ4722) \& National Natural Science Foundation of China (51804348).

*Corresponding author. E-mail address: jiangweiliu@csu.edu.cn. 


\section{Nomenclature}

A contact area

$c \quad$ specific heat

[D] elastic-plastic matrix

$\left[D_{e}\right] \quad$ elastic matrix

$\left[D_{p}\right] \quad$ plastic matrix

$F \quad$ electrode force

$f \quad$ yield stress

$h_{1} \quad$ convective heat transfer coefficient

$h_{2} \quad$ radiative transfer coefficient

$h_{c} \quad$ heat transfer coefficient of cooling

water

$H \quad$ latent heat

I welding current

$j \quad$ current density

$k \quad$ thermal conductivity coefficient

$k_{g} \quad$ thermal conductivity of the gap

$L \quad$ Lorentz constant of materials

$P \quad$ pressure

$q_{c o n v} \quad$ heat flux of convective heat transfer

$q_{\text {rad }} \quad$ heat flux of radiative heat transfer

$r \quad$ external radius of electrode

$r_{c} \quad$ contact radius

$R \quad$ resistance

$t \quad$ welding time

$T$ temperature

$T_{0} \quad$ initial temperature

$T_{a} \quad$ ambient temperature
$T_{m} \quad$ melting temperature of the material

$T_{C} \quad$ temperature at center of copper electrode contact face

$T_{E} \quad$ temperature at edge of copper electrode contact face

$U \quad$ displacement

$U R \quad$ rotational degrees of freedom

Greek symbols

$\alpha \quad$ coefficient of thermal expansion

$\varepsilon_{e} \quad$ elastic strain

$\varepsilon_{p} \quad$ plastic strain

$\varepsilon_{t h} \quad$ thermal strain

$\rho$ density

$\sigma \quad$ stress

$\sigma_{e} \quad$ total electrical conductivity

$\sigma_{g} \quad$ gap conductivity

$\square \quad$ electrical potential

$\Delta l \quad$ typical element dimension

$\Delta t \quad$ time increment

$\Delta \square \quad$ corrections of incremental

electrical potential

Superscript

$L \quad$ liquidus

$S \quad$ solidus

$x \quad x$-direction

$y \quad \mathrm{y}$-direction

$z \quad$ z-direction 


\section{Introduction}

The lightweight and high strength materials have been widely used in automotive industry to develop more fuel-efficient vehicles while guaranteeing improved occupant safety and durability [1]. Compared to the traditional low carbon steel, the advanced high strength steels (AHSS) like the dual-phase (DP) steels have the excellent properties such as high strength, low yield rate, high working hardening rate, high strain energy absorbing characteristics and son on [2]. Using AHSS instead of low carbon steel in the structural parts of vehicle body can meet the safety requirement and reduce the plate thickness and weight [3]. As one of the commonly used AHSS, DP steels are increasingly adopted in automotive industry in recent decades $[4,5]$. Meanwhile, the traditional low carbon steel still dominates the complex parts of automotive manufacturing due to its low cost and wide application. Therefore, joining dissimilar steels with different thicknesses are frequently needed for local design requirements in production [6].

RSW is widely used for joining metallic materials in various industries due to its low cost and highly automated [7]. RSW uses the thermal effect of resistance generated by current flowing through the contact surface and adjacent areas of the workpieces to heat it to a molten or plastic state and then form a metal bond. In recent decade, some common problems encountered in RSW of different thicknesses sheets and dissimilar steels in the manufacturing processes were concerned, including the rotor steels [8], AISI 1008 low carbon steel/ DP600 steel [9], BH180-AISI304/BH180-IF7123 steels [10] and stainless steel/non-stainless steel [11]. The effects of RSW parameters on the failure modes are identified, and found that excessive current and energizing time reduced the peak load of the joint. As RSW is a complex process which involves electrical, thermal, mechanical and metallurgical phenomena and many parameters are usually unmeasurable, the numerical simulation provides a cost-effective way to study RSW process. Charde [12] proved that the force profiles influence the fusion process directly which affects the heat generation as well as the heat diffusion in the RSW process. Karimi et al. [13] improved the RSW model with aluminum alloy 6061-T6 and found that in the modeling of aluminum alloys spot welding, the thermal contact conductance has a major role in nugget enlargement during the welding process and cannot be ignored. Wan et al. [14] improved the RSW model with 
both electrical contact resistance and thermal contact resistance for welding aluminum alloy to zinc-coated steel, and studied the nugget development and intermetallic compound growth during RSW process.

However, the RSW of dissimilar steels still suffered some serious drawbacks, such as nugget shifting to one workpiece and frequent electrodes failure. When the differences (e.g., physical properties and thickness) between the workpieces increase, the degree of weld nugget shifting would become serious, leading to the unqualified weld nugget [15]. For the dissimilar steels, as the chemical composition, physical and mechanical properties are quite different [16], the nugget may shift to the side with greater electrical resistivity although having same thickness; while for the same steel with different thicknesses, the nugget may shift to the thicker side [17]. For the welding joint with material combination of SAE1004, SAE1004 and DP600, the critical thickness combination was 0.6, 1.8 and 2.0 $\mathrm{mm}$ [15]. On the other hand, the RSW of dissimilar steels has the unbalanced heat flux from the weld nugget to the electrode, and thus the electrode easily experiences thermal excursion and deformation under the high temperature, leading to the requirement for frequent redressing or replacement of the weld cap [18]. A service life approach could be employed to estimate the allowable heat flux density for a metallic component before failure [19]. Parker [20] examined the electrode tip growth mechanisms when welding uncoated low carbon and galvanized steels. Chatterjee et al. [21] described the main factors affecting electrode wear when RSW coated steels. It was observed that at 500 550 $\square$ and under the pressure of 50 55Mpa, the high-temperature plastic deformation and pitting occurred after a few welding cycles [22].

To avoid the above defects, REW was developed on the basis of RSW to weld a connecting element such as rivet to the material below by heating them under mechanical loads through a resistive thermal effect [23]. By adding a welding element of the similar material with the lower workpiece, the welding element is directly connected with the lower workpiece to form a nugget, the upper workpiece is mechanically locked by the welding element. As compared to the RSW joints, REW could mitigate the nugget shifting between the workpieces, and forming a joint at lower welding currents [24]. Meschut et al. [25] experimentally compared the shear strength of REW joint with other connection 
technologies, and found that the maximum shear load of REW was limited by the surface material part instead of the joining elements. Ling et al. [26] compared the REW and traditional RSW process under different currents, and found that RSW could barely join $\mathrm{Al}$ 6061 and boron steel, but REW could join the metals reliably with a high tensile shear force. Manladan et al. [27] compared the nugget formation of magnesium alloy and austenitic stainless steel under RSW and REW, and found that the nugget of REW consisted of a peripheral fusion zone on the stainless steel side and the main fusion zone.

The REW process involves multiple intermetallic contacts, leading to more complex dynamic current flow, heat generation and transfer, nugget growth. Manladan et al. [24] simulated the thermal contacts with heat generation between two solids to study the thermal characteristics due to interfacial conditions based on the thermal-electrical analogy. Chen et al. [28] established an experimental setup to measure thermal contact resistance at high temperature based on steady state method, found that the thermal contact resistance decreased when the interface temperature increases and the interface pressure decreases, and the effects of pressure on thermal contact resistance was much lower at high temperature. Furthermore, the contact interactions in the REW process is more complicated compare with RSW process, including the electrode-workpiece, electrode-welding element, welding element-workpieces, workpiece-workpiece. Two surfaces in contact with each other have the same or similar contact stiffness and may be deformed, which directly affects the current distribution and heat generation during the welding process. Therefore, REW increases the thermal contacts between the interfaces that increases the coupled electrical, thermal, mechanical and metallurgical phenomena. As the multiple interfacial thermal contact behaviors with heat generation of REW are unclear yet, it is essential to reveal the underlying mechanisms related to the nugget shifting and mitigation with REW for dissimilar steels.

In this study, by considering the multiple interfacial contacts and hereof electrical, thermal and mechanical behaviors of the welding process, a 3D fully coupled method was established on Abaqus and employed to simulate RSW and REW processes of DP600 and Q235 steels. Due to the introduce of an element in REW, the effects of multiple interfacial interactions on the nugget formation and growth, and the thermal excursion to the copper 
electrode were studied. By varying the insulation coatings on different interfacial contacts between the element and workpieces, the nugget shifting phenomena were further studied. This study will be helpful to understand the fundamentals on the advantages of REW over RSW in improving nugget shifting and extending electrode life, and provide a guidance for welding schedule development of the REW of dissimilar steels.

\section{Mathematical model}

\subsection{Model description}

In this study, just a quarter of the domain is modelled due to symmetry along the $x-y$ plane and the $y-z$ plane. Fig. 1 shows the schematic sketches for the RSW and REW with the fixed 3D $x-y-z$ coordinate system. During the welding process, the workpieces to be joined are squeezed by a pair of flat-tip electrodes along the $y$-direction and the welding current flows directly from the upper electrode in RSW or element in REW to the lower electrode through the workpieces. Thereby the sufficient heat is generated to heat, melt and fuse the metal workpieces together by the Joule heating due to both bulk material resistance and interfacial resistance (electrode/workpieces interfaces and workpiece/workpiece faying interface). It is a process involving mechanical squeezing, electrical current flow, water cooling, material heating, melting and solidification, and many other physical phenomena. The following assumptions are adopted in this model:

1) Materials of workpieces and electrodes are homogeneous and isotropic following the Von Mises yield criterion.

2) The magnetic field generated by the current flowing is ignored.

3) The convective heat transfer in the molten pool is ignored due to the weak melt flow.

4) The electrode pressure is uniformly applied to the electrode shaft section. 


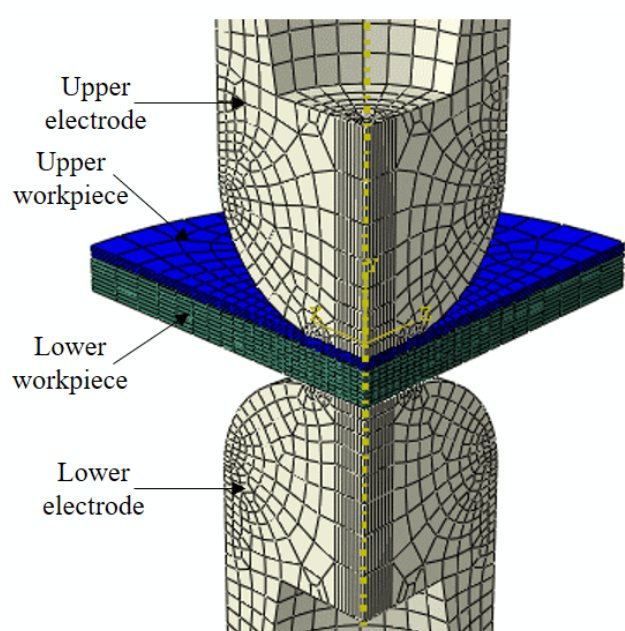

RSW

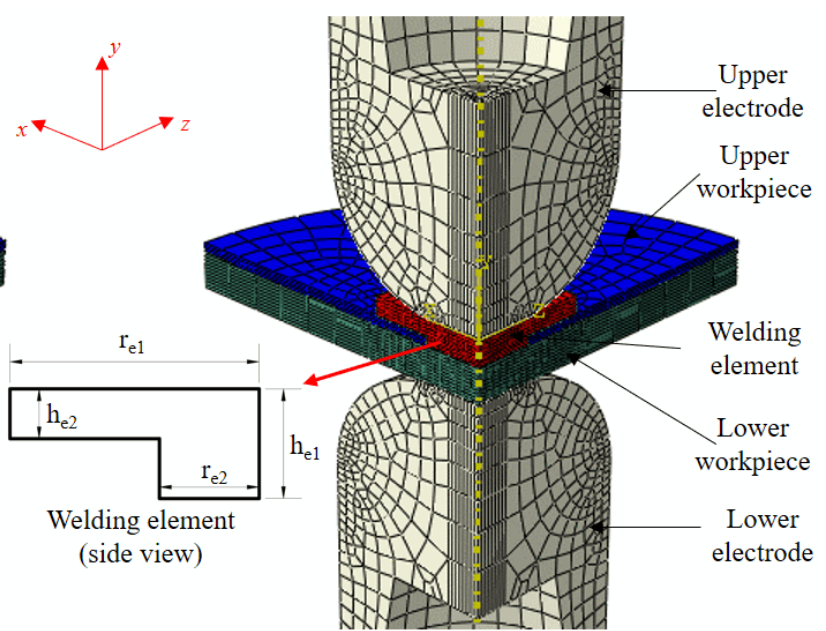

REW

Fig.1 The schematic sketches for the RSW and REW systems.

\subsection{Governing equations}

The governing equations for the thermal, electrical, mechanical transport phenomena employed in the present work are given below.

(1) Thermal continuity

$$
\rho c^{*} \frac{\partial T}{\partial t}=\frac{\partial}{\partial x}\left(k \frac{\partial T}{\partial x}\right)+\frac{\partial}{\partial y}\left(k \frac{\partial T}{\partial y}\right)+\frac{\partial}{\partial z}\left(k \frac{\partial T}{\partial z}\right)+\frac{j_{x}^{2}+j_{y}^{2}+j_{z}^{2}}{\sigma_{e}}
$$

where, the latent heat due to the phase transition of the material can be treated with the increment of the equivalent specific heat capacity, and the following expression can be used:

$$
c^{*}(T)= \begin{cases}c_{S}(T), & T<T_{S} \\ \frac{c_{S}(T)+c_{L}(T)}{2}+\frac{H}{T_{L}-T_{S}}, & T_{S} \leq T \leq T_{L} \\ c_{L}(T) & T>T_{L}\end{cases}
$$

where, $T$ is the temperature; $j_{x}, j_{y}$, and $j_{z}$ are $x$-, $y$-, $z$ - direction current density. The input material properties include density $\rho$, specific heat $c$, latent heat $H$, solidus temperature $T_{s}$ and liquidus temperature $T_{L}$, thermal conductivity $k$, electrical conductivity $\sigma_{e}$.

(2) Current continuity

$$
\frac{\partial}{\partial x}\left(\sigma_{e} \frac{\partial \phi}{\partial x}\right)+\frac{\partial}{\partial y}\left(\sigma_{e} \frac{\partial \phi}{\partial y}\right)+\frac{\partial}{\partial z}\left(\sigma_{e} \frac{\partial \phi}{\partial z}\right)=0
$$

where, $\phi$ is electrical potential.

(3) Ohm's law 


$$
j_{x}=-\sigma_{e} \frac{\partial \phi}{\partial x}, j_{y}=-\sigma_{e} \frac{\partial \phi}{\partial y}, j_{z}=-\sigma_{e} \frac{\partial \phi}{\partial z}
$$

(4) Constitutive equation

In the elastic period

$$
\begin{gathered}
\sigma=D \varepsilon_{e}+\varepsilon_{t h}-C T \\
D=D_{e} \\
C=-D_{e}\left(\alpha+\frac{\partial D_{e}^{-1}}{\partial T} \sigma\right)
\end{gathered}
$$

In the plastic period

$$
\begin{gathered}
\sigma=D \varepsilon_{e}+\varepsilon_{p}+\varepsilon_{t h}-C T \\
D=\left[D_{p}\right] \\
C=-\left(\left[D_{p}\right] \alpha+\left[D_{p}\right] \frac{\partial D_{e}^{-1}}{\partial T} \sigma-D_{e}\left\{\frac{\partial f}{\partial \sigma}\right\}\left\{\frac{\partial f_{0}}{\partial T}\right\} / U\right) \\
\varepsilon_{t h}=\alpha T
\end{gathered}
$$

where, $\sigma$ is the vector of stress, $\varepsilon_{e}, \varepsilon_{p}$ and $\varepsilon_{t h}$ are the elastic, plastic and thermal strain, respectively, $[D]$ is the elastic-plastic matrix, $\left[D_{e}\right]$ is the elastic matrix and $\left[D_{p}\right]$ is the plastic matrix, $U$ is the displacement.

\subsection{Boundary conditions}

The boundary conditions for the solution of RSW/REW model are given below.

(1) Symmetrical $x-z$ plane and $y-z$ plane

$y-z$ plane $(x=0)$

$$
\begin{gathered}
U_{x}=U R_{y}=U R_{z}=0 \\
\frac{\partial T}{\partial x}=0 \\
\frac{\partial \phi}{\partial x}=0
\end{gathered}
$$

$x-y$ plane $(z=0)$ 


$$
\begin{gathered}
U_{z}=U R_{x}=U R_{y}=0 \\
\frac{\partial T}{\partial z}=0 \\
\frac{\partial \phi}{\partial z}=0
\end{gathered}
$$

where, $U_{x}$ and $U_{y}$ are the translational degrees of freedom along the $x$ and $y$ directions, respectively; $U R_{x}, U R_{y}$ and $U R_{z}$ are the rotational degrees of freedom on the $x, y$ and $z$ axis, respectively.

(2) Top surface of the upper electrode

$$
\begin{gathered}
P=\frac{F}{\pi r^{2}} \\
-\sigma_{e} \frac{\partial \phi}{\partial y}=\frac{I}{\pi r^{2}}
\end{gathered}
$$

where, $P$ is the pressure; $F$ and $I$ are the electrode force and welding current applied on the upper electrode; $r$ is the radius of the applied current and force.

(3) External surfaces of workpieces and electrodes

$$
-k \frac{d T}{d y}=\frac{j_{x}^{2}+j_{y}^{2}+j_{z}^{2}}{\sigma_{e}}-q_{c o n v}-q_{r a d}
$$

The heat loss due to convection is calculated by:

$$
q_{c o n v}=h_{1}\left(T-T_{a}\right)
$$

where, $q_{\text {conv }}$ is the heat fluxes of convection heat transfer; $h_{1}$ is the convective heat transfer coefficient; $T_{a}$ is the ambient temperature.

At elevated temperature, radiation heat transfer plays the role part in heat loss, which can be considered as:

$$
q_{\text {rad }}=h_{2}\left(T-T_{a}\right)
$$

where, $q_{\text {rad }}$ is the heat fluxes of radiative heat transfer; $h_{2}$ is the radiative transfer coefficient. (4) Internal flow tube of electrodes

The forced convection is caused by the cooling water flowing through the internal tube of electrodes. To simplify the calculation, it is assumed that the heat transfer coefficient 
along the underside surface of electrode is constant.

$$
-k \frac{d T}{d y}=h_{c}\left(T-T_{a}\right)
$$

where, $h_{c}$ is the heat transfer coefficient of cooling water.

\subsection{Interfacial contact conditions}

As shown in Fig. 2, REW involves six contact interfaces: (1) the element/lower workpiece, (2) the upper electrode/element, (3) the element/lower workpiece, the elementupper workpiece (4) and (5), the workpiece-workpiece (6). The contact electrical and thermal resistances play a decisive role in the distribution of the current and temperature fields during the welding.

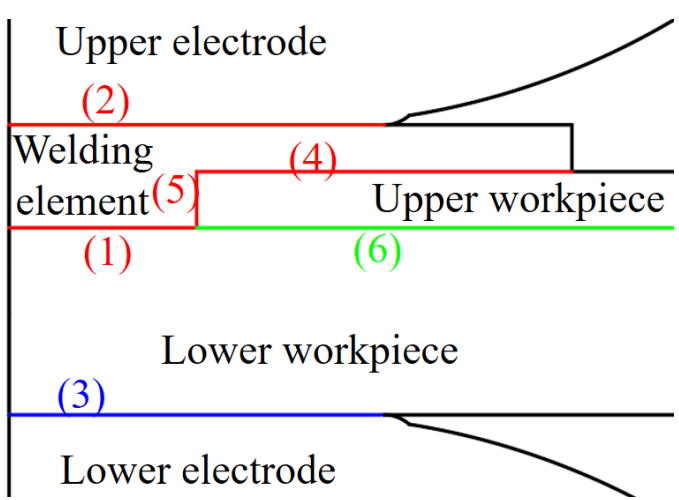

Fig. 2 Contact interactions in the REW process.

In some simulation, a very thin layer of grids is artificially used as the contact surface, which have the specific electrical properties for simulating the heat generation with contact resistance [29]. However, the effect of gap on resistance cannot be effectively considered. Meanwhile, as a layer of grids are introduced in the model, the temperature and current density distributions may be distorted due to the suddenly varied properties. Therefore, in this study, the gap conductivity method is used to simulate the contact resistance. The relationship between voltage drop across a metal contact interface and contact resistance is presented in Kohlrausch's model. Based on this model, Li et al. [30] proposed the microscopic contact theory that was satisfactory in RSW of low carbon steel. Thus, the voltage drop across the contact interface in this model can be estimated as:

$$
\Delta \phi^{2}=4 L T_{m}{ }^{2}-T_{0}^{2}
$$

where, $\Delta \square$ is the voltage drop on the contact interface; $T_{m}$ is the melting temperature of the material; $T_{0}$ is the initial temperature; $L$ is the Lorentz constant of materials. For most metals, 
$L=2.0 \times 10^{-8}\left(\mathrm{~V}^{2} / \mathrm{K}^{2}\right)[31]$.

Contact electrical conductance can be expressed as gap conductance:

$$
\sigma_{g}=\frac{1}{R A}
$$

where, $\sigma_{g}$ is the gap conductivity; $R$ is the resistance per unit area, and $A$ is the contact area.

It can be derived from ohm's law:

$$
\begin{gathered}
R=\frac{\Delta \phi}{I} \\
\sigma_{g}=\frac{I}{2 \pi r_{c}^{2} \sqrt{L T^{2}-T_{0}^{2}}}
\end{gathered}
$$

It should be noticed that Eq. (27) is proposed based on the assumption that the metal in the contact region (represented by the radius $r_{c}$ ) is in close contact. Therefore, the contact resistivity required in the electrothermal analysis can be obtained by the geometric information at the contact interface and the temperature-related physical parameters. When the temperature is higher than the melting point, the contact resistance on the contact interface disappears, and the resistivity of the contact area is the bulk resistivity of the workpiece.

In addition, the contact pressure also affects the contact resistance, so the impact of the contact surface clearance on the contact resistance is considered in this model. A large contact pressure leads to the reduced gap and elevated gap conductivity. When the gap exceeds the critical value, the gap conductivity becomes zero.

The thermal conductivity of metal follows Wiedemn-Franz law [32]:

$$
\frac{k_{g}}{\sigma_{g}}=L T
$$

where, $k_{g}$ is thermal conductivity of the gap. The thermal contact resistance corresponding to the contact resistance can be calculated by Eq. (28).

\subsection{Numerical method}

In this study, the simulation starts with the mechanical analysis of the squeezing stage, which provides the initial contact conditions under the electrode force for the following 
welding stage. During the electrical-thermal-mechanical coupled analysis in the welding stage, the electrical current equations subject to the boundary conditions are first solved to obtain the current distribution within the workpieces. Secondly, the energy conservation equation with Joule heating through the whole calculation domain is solved subject to the thermal boundary conditions, and then the temperature distributions are obtained. Thirdly, the temperature field is applied as the thermal load for the thermal-mechanical analysis. By solving the elastic and plastic equations with the updated temperature-dependent material properties, the stress and strain fields together the deformation of the workpieces are obtained. Newton-Raphson iteration method [33] is used to solve this nonlinear mathematical model and the convergence criterion is

$$
\left|\delta-\delta_{0}\right| / \delta_{0} \leq 10^{-6}
$$

where, $\delta=\phi, T$ and $\sigma$, and $\delta_{0}$ refers to the variable in the last iteration. Then with the updated material properties (including electrical, thermal and mechanical properties) and contact conditions between the parts, the above procedures are repeated until the welding stage is completed. In the subsequent cooling stage, the weldment is cooled and solidified to form the final welding joint.

This highly non-linear computation procedure is performed based on Abaqus. Extensive tests using different grid sizes and time step sizes have been conducted to assure consistent results. The final grid and time step size used in the present study can be seen as the compromised values between the computational time and accuracy. A non-uniform grid point system is employed with finer grid sizes near the contact areas. The finer meshes are set as $0.1 \mathrm{~mm}$. During the entire process, the thermal-electrical-structure linear hexahedral solid elements are used for both electrodes and workpieces. To facilitate the convergence of the analysis, the self-adaptive time step is applied as the whole analysis process is highly coupled with large plastic deformation, and the time increment is defined by:

$$
\Delta t>\frac{\rho c}{6 k} \Delta l^{2}
$$

where, $\Delta l$ is a typical element dimension. The time step size is set as $5 \times 10^{-6} \mathrm{~s}$. 


\section{Model validation}

In order to validate the present model, the REW of $2.0-\mathrm{mm}$ thick 6061 aluminum alloy and 2.0-mm thick boron steel is simulated and compared with the published experiment results [26]. During the welding process, a pre-squeeze cycle is employed with a zero current, and then electrical current ramps up to $9 \mathrm{kA}$. The electrode force is kept constant with a value of $3.6 \mathrm{kN}$, and the welding time is $200 \mathrm{~ms}$. Fig. 3 compares the cross sections of experimental and calculated REW joints. As shown in Fig. 3 (a), the nugget of REW joint is marked in the red dotted line, which is apparently formed by the welding element and the lower workpiece. The upper workpiece of aluminum alloy is partly melted around the element. As shown in Fig. 3 (b), the nugget zone between the element and lower workpiece is represented with the gray area in the center of the joint (i.e., the area with the temperature higher than $1500 \square$ ). When the temperature exceeds $600 \square$, the aluminum alloy has also melted around the element. It is clear from both the experimental and calculated joints that the nuggets are just located beneath the element and obviously shift downward with a higher penetration rate within the lower workpiece. Therefore, the simulation results are consistent with the experiment by comparing the calculated nugget dimensions and shifting phenomena.

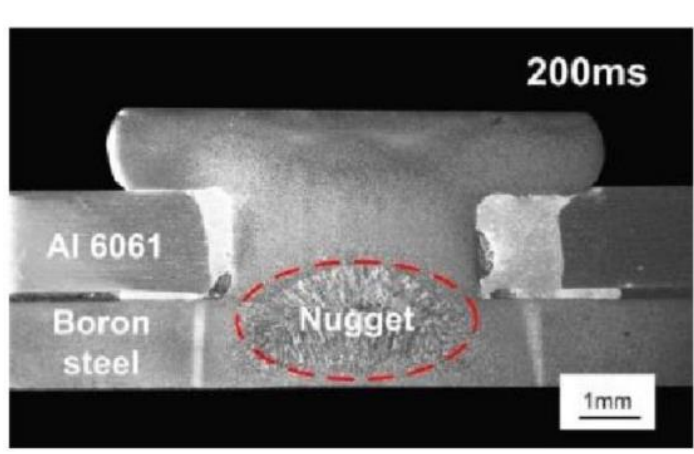

(a)

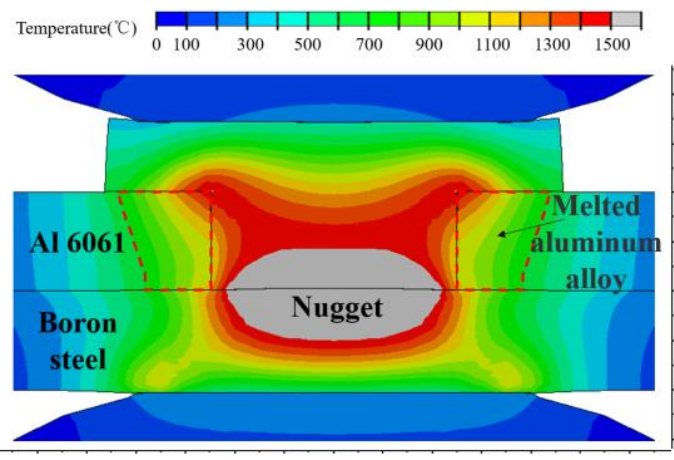

(b)

Fig. 3 The comparison of 6061 aluminum alloy-boron steel joint with REW: (a) experimental result [26]; (b) simulation result.

\section{Results and discussion}

\subsection{Material properties}

In this study, the materials of the upper and lower workpieces are DP600 and Q235, 
respectively. The welding element in the REW process is made of Q235, and the geometrical parameters are $r_{e l}=7 \mathrm{~mm}, r_{e 2}=2 \mathrm{~mm}$ and $h_{e l}=0.5 \mathrm{~mm}$ (referring to Fig.1). Electrodes is made from $\mathrm{ZrCu}(\mathrm{C} 15000)$ with a face diameter of $8 \mathrm{~mm}$ and weld face radius of curvature of $25 \mathrm{~mm}$. The density and poisson's ratio of C15000 are assumed to be constants, i.e., $8900 \mathrm{~kg} / \mathrm{m}^{3}$ and 0.32 , respectively. The chemical composition of DP600 and Q235 is shown in Table 1. According to the chemical composition in Table 1, the young's modulus, thermal conductivity and electrical conductivity of DP600 steel at different temperatures are calculated. Thus the temperature-dependent mechanical, thermal and electrical properties of C15000, DP600 and Q235 are shown in Fig. 4.

Table 1 Chemical composition of DP600 and Q235

\begin{tabular}{ccccccc}
\hline & $\mathrm{Mn}$ & $\mathrm{Si}$ & $\mathrm{C}$ & $\mathrm{Al}$ & $\mathrm{Cr}$ & $\mathrm{Fe}$ \\
\hline DP600 & 0.4 & 0.14 & 0.11 & 0.02 & 0.21 & Balance \\
Q235 & 1.0 & 0.4 & 0.14 & 0.04 & 0.02 & Balance \\
\hline
\end{tabular}



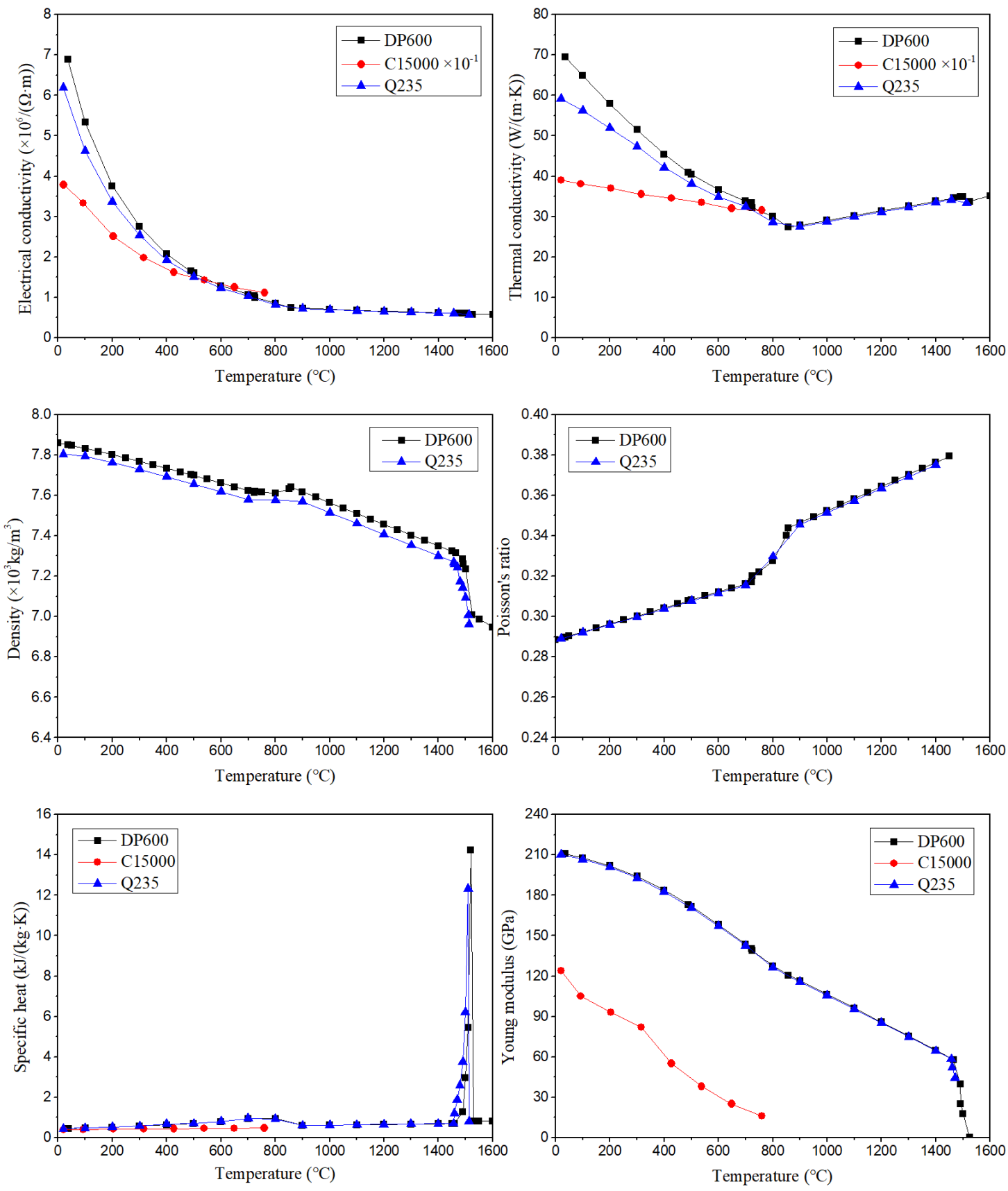

Fig. 4 The temperature-dependent material properties of DP600, copper and Q235.

\subsection{RSW/REW of DP600 and Q235 workpieces}

For welding of DP600 and Q235 workpieces, the welding parameters are selected following the rules given in Ref. [34] and shown in Table 2. The electrode force is kept at $3.5 \mathrm{kN}$ during the whole welding process. The welding current for RSW and REW are different and determined with the aim to form a suitable weldment with the upper electrode temperature less than $550^{\circ} \mathrm{C}$ [23]. 
Table 2 The operating conditions for welding of DP600 and Q235 workpieces.

\begin{tabular}{cccccc}
\hline Cases & $\begin{array}{c}\text { Welding } \\
\text { method }\end{array}$ & $\begin{array}{c}\text { DP600 } \\
\text { thickness }(\mathrm{mm})\end{array}$ & $\begin{array}{c}\text { Q235 thickness } \\
(\mathrm{mm})\end{array}$ & $\begin{array}{c}\text { Current } \\
(\mathrm{kA})\end{array}$ & $\begin{array}{c}\text { Welding } \\
\text { Time (ms) }\end{array}$ \\
\hline (a) & RSW & 2.0 & 2.0 & 14 & 300 \\
(b) & RSW & 0.6 & 2.0 & 14 & 200 \\
(c) & REW & 0.6 & 2.0 & 6 & 200 \\
\hline
\end{tabular}

Fig. 5 shows the temperature distributions and nugget growth at different instants during RSW/REW of 2.0/0.6-mm thick DP600 and 2.0-mm thick Q235. As shown in Fig. 5 (a), for RSW of 2.0-mm DP600 and 2.0-mm Q235, the high-temperature zone first appears at contact surfaces of the copper electrode-workpieces and the faying interface (i.e., $t=50 \mathrm{~ms}$ and $t=100 \mathrm{~ms}$ ) due to the concentrated contacts in these areas. Then the central high-temperature region between the faying interface of workpieces gets larger and forms the nugget (i.e., $t=200 \mathrm{~ms}$ ). Finally, the nugget grows to its maximum size and the welding is completed at $t=300 \mathrm{~ms}$. Due to the small difference in volume resistivity between the workpieces, the temperature of the upper workpiece after welding is only slightly higher than that of the lower workpiece. As shown in Fig. 5 (b), for RSW of 0.6-mm DP600 and 2-mm Q235, the high-temperature zone first appears at upper workpiece (i.e., $t=10 \mathrm{~ms}$ ). The metal is first melted around the periphery of faying interface instead of the center part due to the deformation of thin upper workpiece (i.e., $t=50 \mathrm{~ms}$ and $t=100 \mathrm{~ms}$ ). The nugget size in the upper workpiece is much shallower than that in the lower one, namely the nugget shifts downward the lower workpiece (i.e., $t=200 \mathrm{~ms}$ ). In addition, as the nugget in the upper workpiece is closer to the water-cooled electrode, the heat lose is stronger in the thin plate side, which also contributes to the shallow nugget. However, the size of the nugget has not reached the ideal state at $200 \mathrm{~ms}$. In contrast, for REW of 0.6-mm DP600 and 2mm Q235 shown in Fig. 5 (c), the Joule heat initiates at the faying interface between the welding element and the lower workpiece (i.e., $t=10 \mathrm{~ms}$ ), and then the melted zone is formed (i.e., $t=50 \mathrm{~ms}$ and $t=100 \mathrm{~ms}$ ) within this narrow area with a more concentrated heat generation. The melted zone continues to grow and eventually forms the final nugget which width is almost equal to the welding element diameter (i.e., $t=200 \mathrm{~ms}$ ). In REW, 
the significant nugget shifting between the workpieces is mitigated.

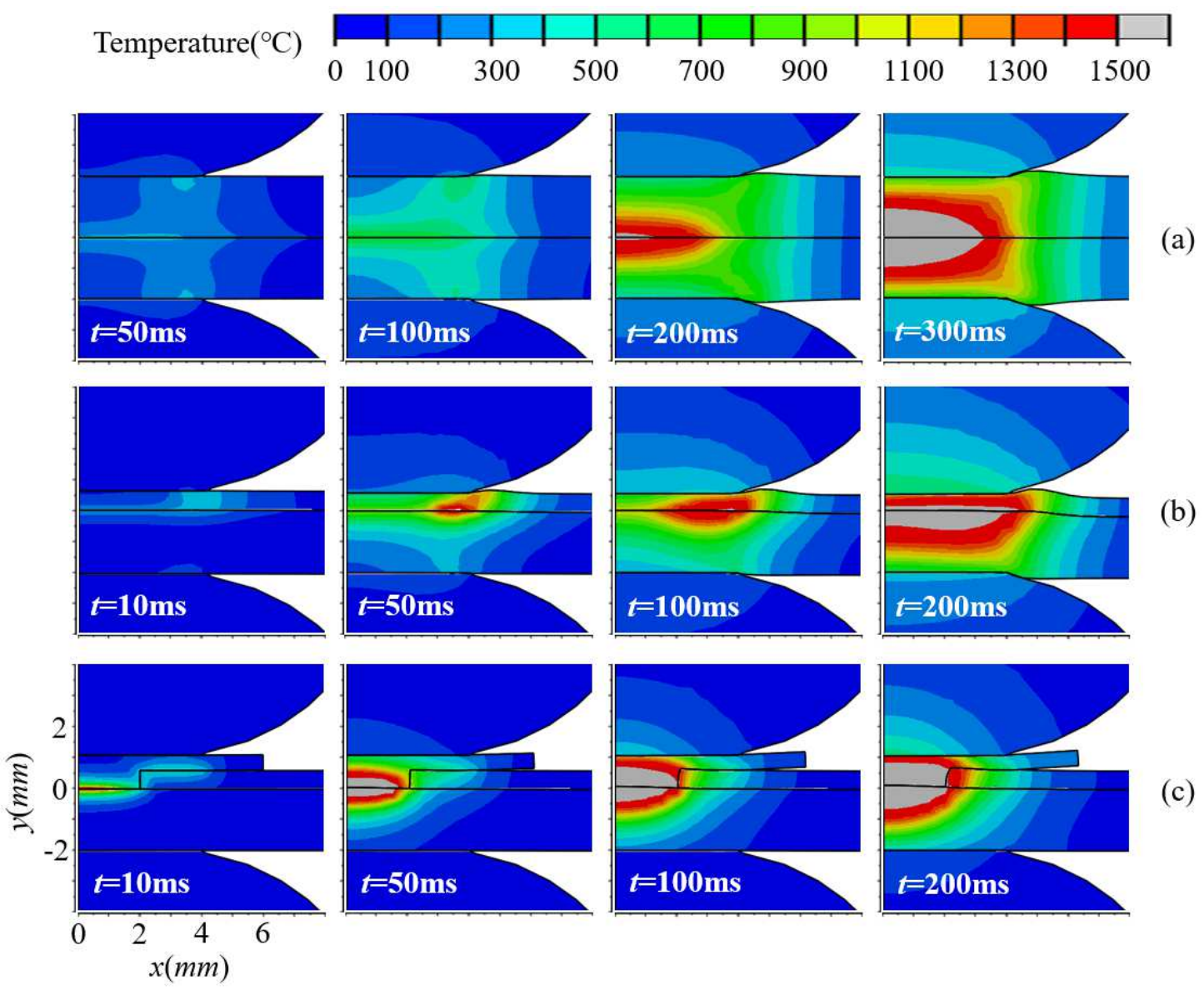

Fig. 5 Temperature distributions and nugget growth during RSW/REW of DP600 and Q235with different thickness:(a) RSW 2-mm DP600/2-mm Q235; (b) RSW 0.6mm DP600/2-mm Q235; (c) REW 0.6mm DP600/2mmQ235.

The copper electrode is in contact with the workpiece at a higher temperature, which indicates that the electrode cap is vulnerable to damage due to the high temperature or adhesion to the molten workpiece. It is obvious that at the end of welding, in RSW 2-mm DP600/2-mm Q235 (Fig. 5(a)), the temperatures of both the upper and lower electrodes are lower than $550 \square$. For $0.6-\mathrm{mm}$ DP600, due to the thinner upper workpiece, a higher temperature occurs at the end face of the electrode due to the larger heat flux density from the faying surface between the workpieces. In RSW 0.6-mm DP600/2-mm Q235 (Fig. 5(b)), the highest temperature in upper electrode exceeds $550^{\circ} \mathrm{C}$. When the copper electrode is subjected to the high temperature above $500 \sim 550^{\circ} \mathrm{C}$, the plastic deformation is easy to occur, 
which would lead to a decrease of nugget size and even the joint failure [22, 35]. In REW 0.6mm DP600/2mm Q235 (Fig. 5(c)), however, the temperature of the upper electrode is much higher but does not exceed 550 $\square$ when the welding is completed at $t=200 \mathrm{~ms}$. Therefore, when welding DP600 and Q235 with a thickness ratio of 0.3, the electrode temperature in REW process is significantly reduced, indicating an extended electrode life in REW.

To further explain the formation and mitigation of the nugget shilfting phenomena shown in Fig. 5, Fig. 6 (a) and (b), respectively, presents the corresponding distributions of pressure and current density along the faying interface between the workpieces or element/workpiece. It is clearly found that RSW of 0.6-mm DP600 initially has the Mshaped distributions in current density (i.e., $t=50 \mathrm{~ms}$ ) with a significantly higher current density beneath the edge of electrode tip, indicating a hot spot and metal melting in this region (referring to Fig. 5 (b)). This is because subject to the high thermal expansion and concentrated contact beneath the edge of electrode tip, the thin DP600 workpiece is obviously deformed, leading to the concentrated pressure and thus concentrated current around the periphery of faying interface $(2.5 \mathrm{~mm}<\mathrm{x}<4.0 \mathrm{~mm})$. As a result, for RSW of 0.6-mm DP600, the electric energy spreads outwards at the faying surface with a result of the shallow and wide nugget within the upper workpiece, leading to the nugget shifting downwards as compared to the other cases. At the latter stage of welding ( $t=100 \mathrm{~ms})$, the distortions of the current and stress distributions for RSW are significantly reduced with the heat generation located in the center regions, leading the final nugget fomation as shown in Fig. 5. In contrast, the current density for REW of 0.6-mm DP600 is well concentrated in the center region $(x<1.5 \mathrm{~mm})$ due to the presence of welding element as compared to the other cases. As a result, REW has the more concentrated heat generation at the faying interfce of welding element/lower workpiece, leading to the rapid nugget formation without the shifting phenomenon. 

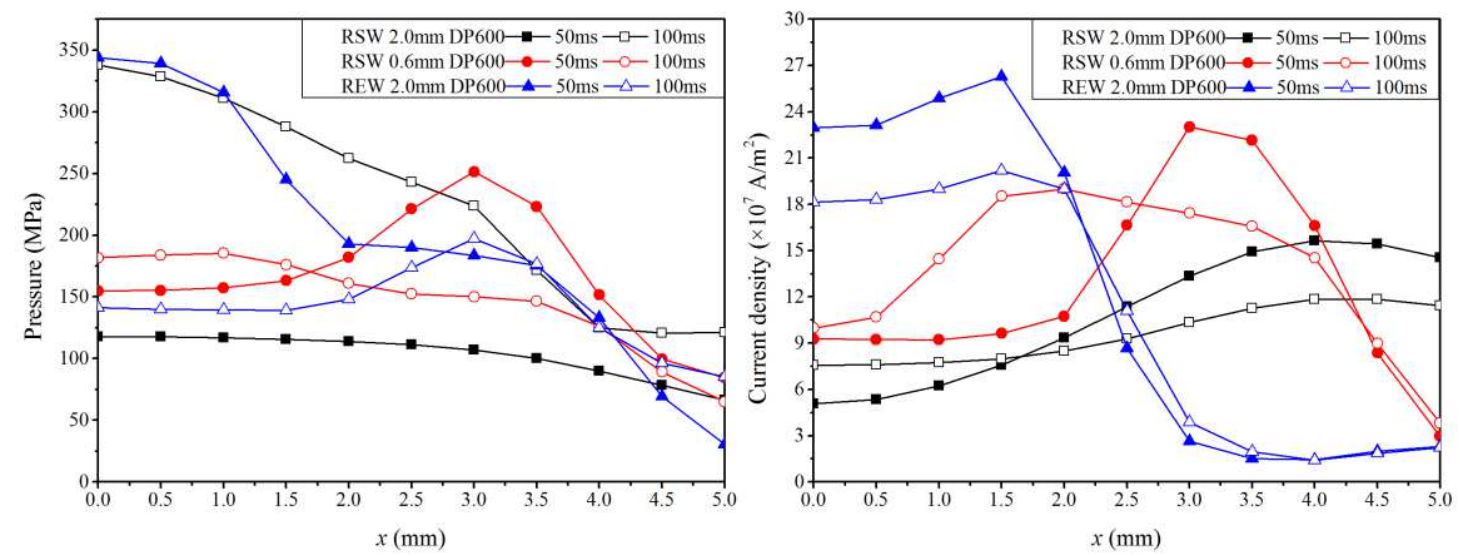

Fig. 6 The pressure and current density distributions along the interface between the workpieces for the cases shown in Fig. 5.

\subsection{Effects of workpiece discrepancies on the nugget formation}

In order to examine the effectiveness of REW on joining the dissimilar steels, the workpieces with different electrical conductivity and thickness are studied with the emphasis on the nugget formation. The welding time for each case is determined at the instants when the temperature at the end of the upper copper electrode just reaches $550^{\circ} \mathrm{C}$.

Fig. shows the nugget thicknesses in both the workpieces with the RSW and REW of 2-mm thick low carbon steels with different electrical conductivity. The electrical conductivity ratio of the upper workpiece and the lower workpiece was set to be 2 to 10 . The electrode force is $3.5 \mathrm{kN}$ and the welding current is $14 \mathrm{kA}$. Obviously, as the difference in conductivity between the upper and lower workpieces increases, the nugget thicknesses decrease with small penetration rates. During the RSW process, as the electrical conductivity ratio is larger than 3 , the nugget ratio would decrease below 0.5 . Therefore, at the high electrical conductivity ratio, the thickness ratio of the upper and lower nuggets becomes small, indicating that the nugget obviously shifts to the lower workpiece with low conductivity. In the REW process, the nugget ratio keeps at about 2.1 although the resistivity ratio increases, which indicates that shifting is significantly reduced with a slight shifting to the upper workpiece due to the addition of rivet-like element. As compared to RSW, the thicknesses of the nugget are significantly increased. In summary, when welding two workpieces with a large electrical conductivity ratio $(\geq 3)$, the REW method can effectively reduce the shifting of the nugget. 


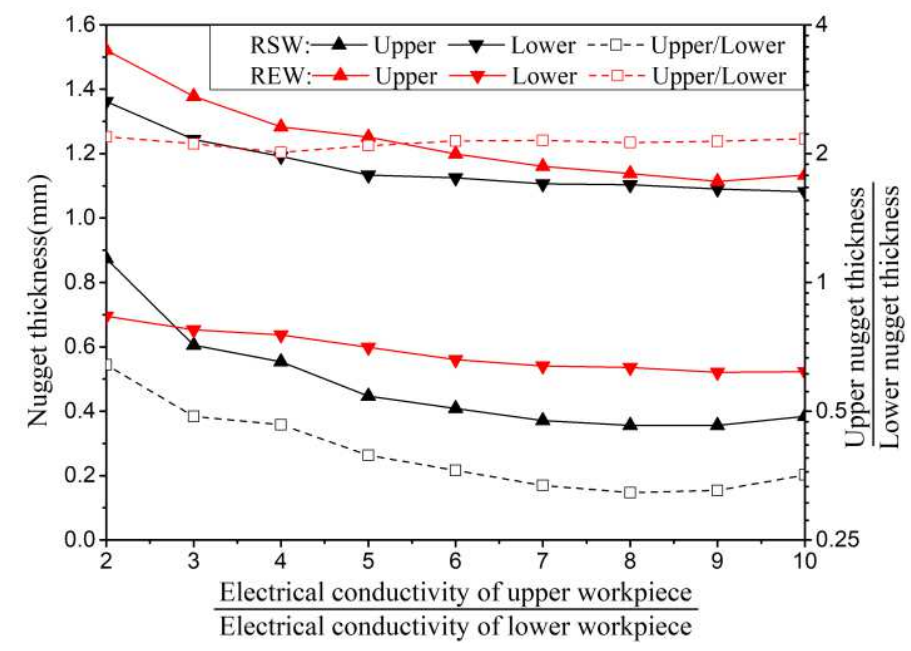

Fig. 7 Nugget thickness under different electrical conductivity ratio of the workpieces. (solid line-nugget thickness, dash line-nugget thickness ratio)

Fig. presents the nugget thickness under different upper workpiece thickness, showing the nugget shifting in the RSW and REW processes with different upper workpiece thicknesses. The upper workpiece thickness was, respectively, set as $0.4 \mathrm{~mm}, 0.6 \mathrm{~mm}$, $0.8 \mathrm{~mm}, 1.0 \mathrm{~mm}, 1.4 \mathrm{~mm}$, and $2.0 \mathrm{~mm}$, while the lower workpiece thicknesses was fixed at $2 \mathrm{~mm}$. The electrode force is $3.5 \mathrm{kN}$ and the welding current is $14 \mathrm{kA}$ for RSW and $6 \mathrm{kA}$ for REW. In the RSW process, as the thickness of the upper workpiece decreases, the size and penetration rate of the nugget decrease, and the nugget shifting becomes serious. Especially, as the thickness of upper workpiece is smaller than $0.8 \mathrm{~mm}$, the nugget in upper workpiece is thinner than $0.12 \mathrm{~mm}$ with the nugget thickness ratio less than 0.5. During the REW process, at the small thickness of the upper workpiece $(0.8 \mathrm{~mm})$, the nugget thicknesses in the lower workpiece and upper workpiece (welding element) are quite identical. When the thickness of the upper workpiece is greater than $1.0 \mathrm{~mm}$, the nugget in the upper workpiece (welding element) is significantly enlarged with an obvious nugget shifting to the upper workpiece. Therefore, it can be concluded that when the thickness of the upper workpiece is less than $0.8 \mathrm{~mm}$, the REW method can reduce the nugget shifting as compared to RSW. However, when the thickness of the upper workpiece is greater than $1.0 \mathrm{~mm}$, the REW method becomes less useful while RSW method could produce the good nugget penetration with the small nugget shifting. In summary, REW shows the great superiority against RSW for welding the workpieces with a large difference in thickness. 


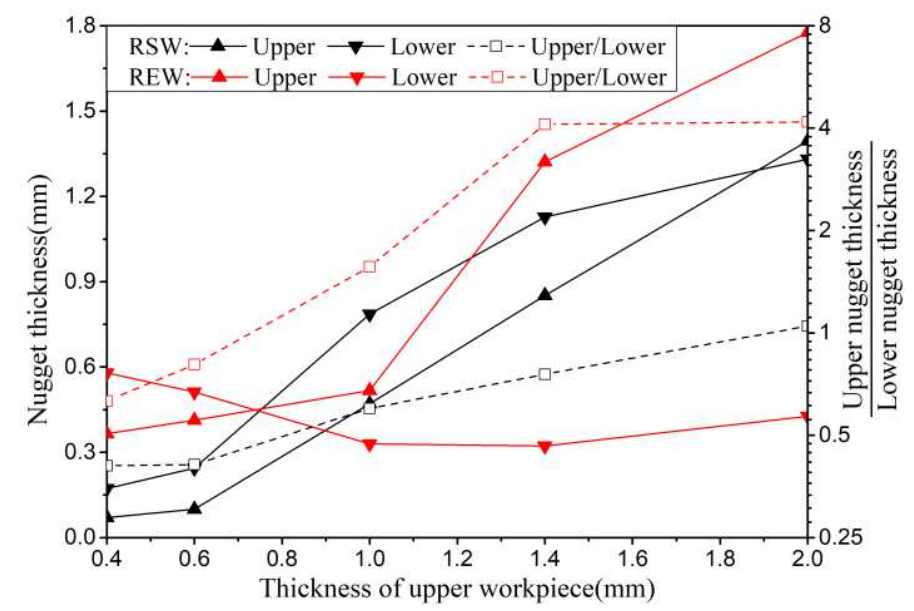

Fig. 8 Nugget thickness under different upper workpiece thicknesses (solid linenugget thickness, dash line-nugget thickness ratio)

\subsection{Effects of interfacial insulation in REW on the nugget formation}

For the REW process, the less heat generation between the welding element and the upper workpiece is required, and the nugget shifting between workpieces should be as small as possible. Therefore, to improve the REW, it is expected to control the current flows by adding some insulation layers on the contact surfaces of the parts and thus the heat generation at the target area.

Fig. shows the distributions of current density and temperature with the nugget dimensions for the REW of DP600 and Q235 workpieces under different insulation conditions at the contact surfaces shown in Fig. 2. The welding current is reduced to $3 \mathrm{kA}$, and the final welding time is $200 \mathrm{~ms}$. As shown in Fig. 9(a), by examining the current density at the initial stage $(t=10 \mathrm{~ms})$ of each the welding process, it is clear that the current flow is significantly affected by the insulation layers. As compared to the non-insulation case (the first column in Fig. 9), the insulated contact surface (5) (the second column in Fig. 9) contributes to blocking the current flow from the side wall of welding element to the upper workpiece, leading to a slight increase in the heat generation at the faying surface. But this phenomenon is not strong enough so that neither of the cases has formed a high current density at the faying surface. As contact surface (4) is insulated (the third column in Fig. 9), the current flow from the electrode toward the upper workpiece is blocked by the insulation layer, leading to the current concentration within the welding element. For 
the insulated contact surfaces (4) and (5) (the forth column in Fig. 9), as the current flows through the welding element, the part of current from the side wall of element to the upper workpiece is further blocked, leading to the more concentrated current at the bottom of the welding element. As shown in Fig. 9(b), the temperature distributions are corresponding to the current density distributions. For the non-insulation case or adding insulation at the surface (5), the nugget is never effectively formed at $t=200 \mathrm{~ms}$ and some Joule heating is generated at the contact surface (4) with a result of the wider thermal affected zone, showing the electrical energy is dispersed (As shown in Fig. 9(c)). As adding insulation at the surface (4), a medium-sized nugget is formed at $t=200 \mathrm{~ms}$ because the current is concentrated underneath the welding element. It is also found that part of the current flows from surface (5) to the workpiece without passing through the faying surface. As further adding insulation at both surfaces (4) and (5), a large-sized nugget is observed at $t=200$ ms due to the more concentrated current flows through the faying surface. However, for the insulated contact surfaces (4) and (5), all the current flowing from the electrode to the upper workpiece is blocked, leading to the higher temperatures in the welding element and the more thermal excursion to electrode. 


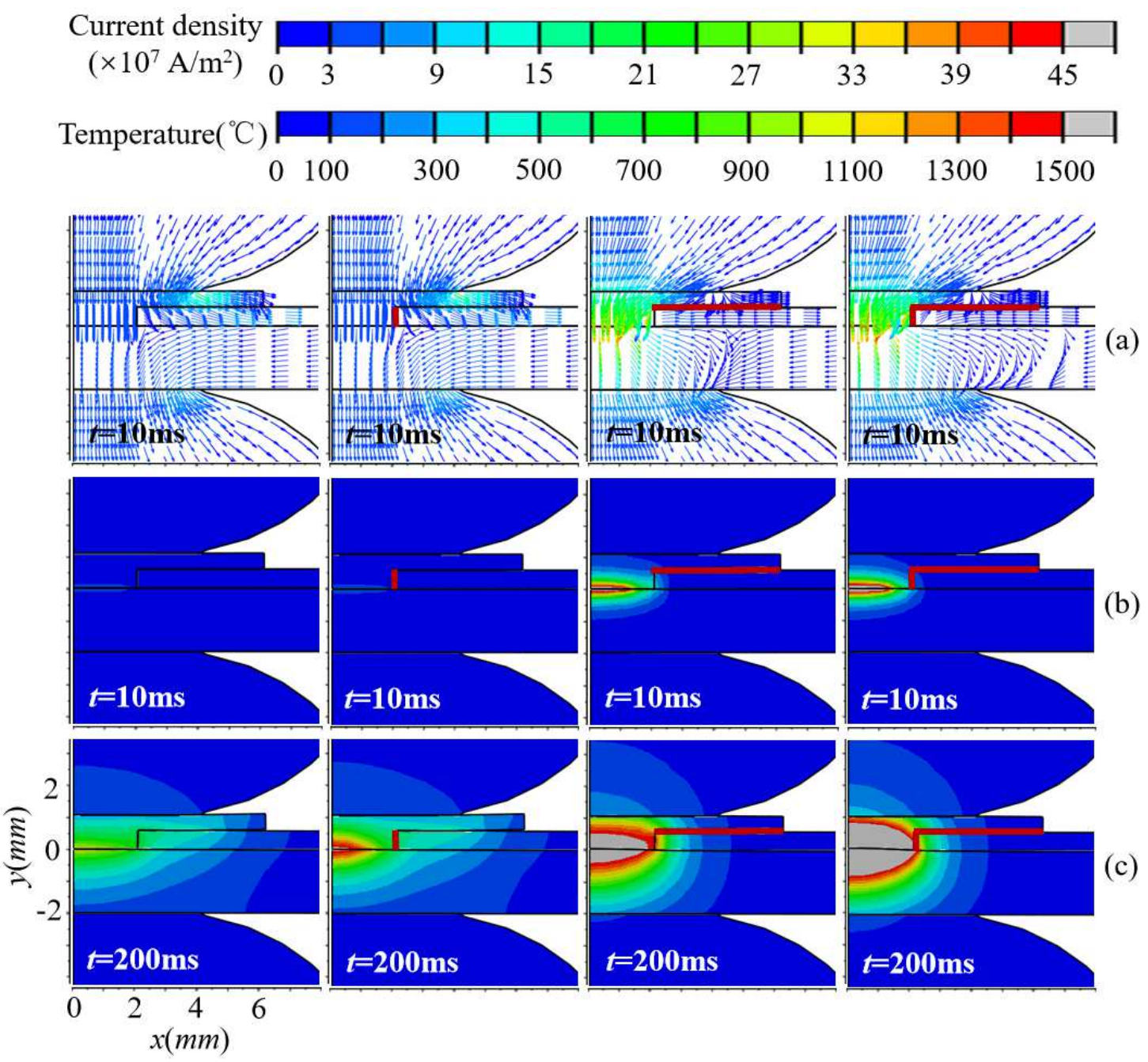

Fig. 9 Distributions of current density and temperature distributions with the nugget dimensions for the REW processes under different insulation conditions: (a) current density at $t=10 \mathrm{~ms}$, (b) temperature at $t=10 \mathrm{~ms}$; (c) temperature at $t=200 \mathrm{~ms}$. (The red solid line refers to the insulation layer)

To further explain the nugget development for the REW of DP600 and Q235 workpieces under different insulation, Fig. 10 shows the corresponding distributions of current density along the faying interface between the workpieces or element/workpiece. At the beginning of the welding stage $(t=10 \mathrm{~ms})$, for the non-insulation case and the insulated contact surface (5), the current density distributions are very similar that are developed evenly along the contact surface, which is much lower than the other cases underneath the welding element $(x<2.0 \mathrm{~mm})$. For the insulated contact surface (4) and the insulated contact surface (4) and (5), the current density becomes much higher while the latter case shows the more concentrated case. At the latter stage $(t=200 \mathrm{~ms})$, as compared 
to non-insulation case, the current density for case with the insulated contact surface (5) significantly increases, resulting in the higher temperature at the contact surface. As adding insulation at the surface (4) or at the surface (4) and (5), due to the formation of nugget on the contact surface, the contact resistance is reduced and the current concentration is reduced that have the $\mathrm{M}$-shaped distributions, which contributes to widening the nugget.

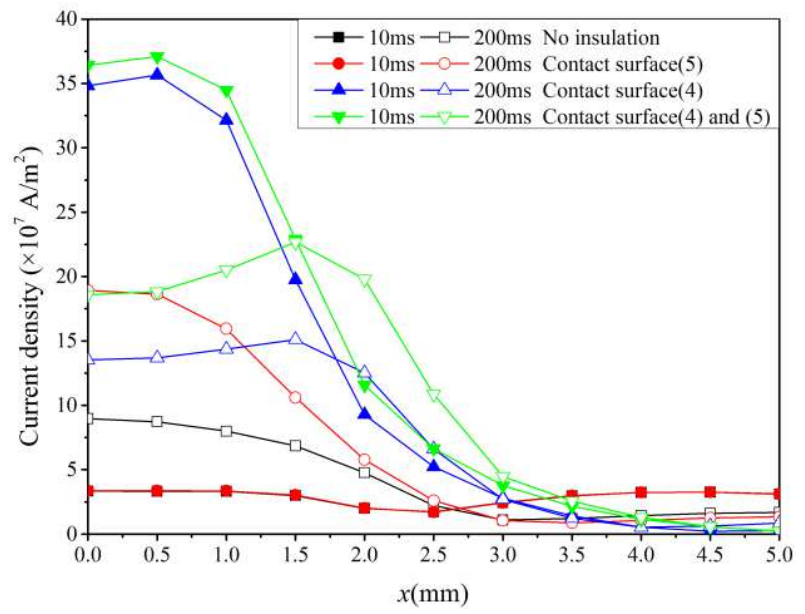

Fig.10 The current density distributions along the interface between the faying interface between the workpieces or element/workpiece.

\section{Conclusion}

Resistance element welding (REW) is a novel joining method developed on the basis of resistance spot welding (RSW) by applying an auxiliary element (i.e. rivet) to connect the lower workpiece and fastening the upper workpiece. In this paper, the three-dimensional finite element models are developed to study underlying physics during RSW and REW processes of DP600 and Q235. The superiority of REW against RSW in dissimilar steels with unequal thickness is elaborated.

In RSW of the thin DP600 and thick Q235, the current concentration initially occurs around the periphery of faying interface due to the thin workpiece deformation, leading to a relatively dispersive energy distribution at the faying surface. As a result, the shallow and wide nugget is formed within the thinner workpiece, leading to the nugget shifting toward the thicker workpiece. In addition, the copper electrode adjacent to the thinner workpiece experiences an extremely high temperature (over 550 $\square$ ) that would reduce the electrode life. For welding of workpieces with equal thickness and large different resistivity, a longer time is required for the RSW process to form a suitable nugget due to the smaller resistivity 
on one side, and the nugget shifts to the workpiece with the high resistivity.

In REW, when adding a welding element inside the thinner workpiece or the workpiece with the low resistivity, the welding current could be concentrated beneath the welding element and thus reduce the nugget shifting. The nugget is only formed at the faying interface between the welding element and workpiece with a smaller welding current and a shorter welding time. The use of REW technology can effectively reduce the electrode temperature and thus extend the electrode life. As compared to RSW, the REW method can effectively reduce the nugget shifting when welding two workpieces with a large difference in thickness (workpiece thickness ratio $\leq 0.4$ ) or welding two workpieces with large resistivity difference (electrical resistivity ratio $\geq 3$ ). Adding an insulation layer could control the current flow and further concentrate the current in the welding element. A largesized nugget is formed by adding an insulation layer between both the contact surfaces of welding element and the upper workpiece. Only adding an insulation layer on the side of the welding element, the effects of insulation layer on the current distribution and welding results are insignificant.

\section{Declarations}

\section{Ethical Approval}

Not applicable.

\section{Consent to Participate}

Not applicable.

\section{Consent to Publish}

Not applicable.

\section{Authors Contributions}

Zhenghua Rao: Conceptualization, Data curation, Formal analysis, Methodology, Writing - original draft, Writing - review \& editing.

Lei Liu: Data curation, Formal analysis, Software, Visualization, Writing - original draft. 
Yaqiong Wang: Data curation, Formal analysis, Software, Writing - original draft.

Liang Ou: Data curation, Software, Validation, Writing - original draft.

Jiangwei Liu: Conceptualization, Project administration, Validation, Writing - review \& editing.

\section{Funding}

This work was supported by Hunan Provincial Natural Science Foundation of China (2020JJ4722) \& National Natural Science Foundation of China (51804348).

\section{Competing Interests}

The authors have no conflicts of interest to declare that are relevant to the content of this article.

\section{Availability of data and materials}

The datasets generated and analyzed during this study are included in this published article, and the raw data are available from the corresponding author on reasonable request.

\section{References}

[1] Marashi P, Pouranvari M, Amirabdollahian S, Abedi A, Goodarzi M. Microstructure and failure behavior of dissimilar resistance spot welds between low carbon galvanized and austenitic stainless steels. Materials Science and Engineering: A. $2008 ; 480: 175-80$.

[2] Movahed P, Kolahgar S, Marashi SPH, Pouranvari M, Parvin N. The effect of intercritical heat treatment temperature on the tensile properties and work hardening behavior of ferrite-martensite dual phase steel sheets. Materials Science and Engineering: A. 2009;518:1-6.

[3] Venezuela J, Liu Q, Zhang M, Zhou Q, Atrens A. A review of hydrogen embrittlement of martensitic advanced high-strength steels. Corrosion Reviews. 2016;34:153-86.

[4] Khan MI, Kuntz ML, Zhou Y. Effects of weld microstructure on static and impact performance of resistance spot welded joints in advanced high strength steels. Science and Technology of Welding and Joining. 2008;13:294-304.

[5] Sun X, Stephens EV, Khaleel MA. Effects of fusion zone size and failure mode on peak load and energy absorption of advanced high strength steel spot welds under lap shear loading conditions. Engineering Failure Analysis. 2008;15:356-67.

[6] Long HQ, Hu YM, Jin XQ, Shao JH, Zhu H. Effect of holding time on microstructure and mechanical properties of resistance spot welds between low carbon steel and advanced high strength steel. Computational Materials Science. 2016;117:556-63.

[7] Andersson 0, Melander A. Prediction and verification of resistance spot welding results of ultra-high strength steels through FE simulations. Modeling Numerical Simulation of Material Science. 2015;5:26.

[8] Zhu ML, Xuan FZ. Correlation between microstructure, hardness and strength in 
HAZ of dissimilar welds of rotor steels. Materials Science and Engineering: A. $2010 ; 527: 4035-42$.

[9] Pouranvari M, Mousavizadeh SM, Marashi SPH, Goodarzi M, Ghorbani M. Influence of fusion zone size and failure mode on mechanical performance of dissimilar resistance spot welds of AISI 1008 low carbon steel and DP600 advanced high strength steel. Materials \& Design. 2011;32:1390-8.

[10] Hayat F. Resistance Spot Weldability of Dissimilar Materials: BH180-AISI304L Steels and BH180-IF7123 Steels. Journal of Materials Science \& Technology. $2011 ; 27: 1047-58$.

[11] Alenus M, Pohjanne P, Somervuori M, Haenninen H. Exploring the Mechanical Properties of Spot Welded Dissimilar Joints for Stainless and Galvanized Steels. Welding journal. 2006;85:p. 305s-13s.

[12] Charde N. Techniques for the improvement of carbon steels welds: under the SISF and DIDF welding schemes using pneumatic- and servo-based electrode actuating systems in resistance spot welding. The International Journal of Advanced Manufacturing Technology. 2017;89:3161-8.

[13] Karimi MR, Sedighi M, Afshari D. Thermal contact conductance effect in modeling of resistance spot welding process of aluminum alloy 6061-T6. The International Journal of Advanced Manufacturing Technology. 2015;77:885-95.

[14] Wan Z, Wang H-P, Wang M, Carlson BE, Sigler DR. Numerical simulation of resistance spot welding of Al to zinc-coated steel with improved representation of contact interactions. International Journal of Heat \& Mass Transfer. 2016;101:74963.

[15] Shen J, Zhang Y, Wang P. Nugget shifting in resistance spot welding of multistackup sheets. Quarterly Journal of the Japan Welding Society. 2011;29:133s-7s.

[16] Jianpeng C, Yanhong YE, Yanjie Z, Dean D. Study on Influences of Groove Type on Welding Residual Stress and Deformation in Q345/SUS304 Dissimilar Steel Butt-welded Joints. Journal of Mechanical Engineering. 2015;51:55.

[17] Wang YX, Zhang P, Wu Y, Hou ZG. Analysis of the Welding Deformation of Resistance Spot Welding for Sheet Metal with Unequal Thickness. Journal of Solid Mechanics and Materials Engineering. 2010;4:1214-22.

[18] Wang Y, Rao Z, Wang F. Heat evolution and nugget formation of resistance spot welding under multi-pulsed current waveforms. The International Journal of Advanced Manufacturing Technology. 2020;111:1-13.

[19] Rao Z, Bao S, Liu X, Taylor RA, Liao S. Estimating allowable energy flux density for the supercritical carbon dioxide solar receiver: A service life approach. Applied Thermal Engineering. 2020:116054.

[20] Parker J. Relative contribution of electrode tip growth mechanisms in spot welding zinc coated steels. welding in the world le soudage dans le monde. 1996: 4 (37) : 186-93.

[21] Chatterjee KL, Waddel1 W. Electrode wear during spot welding of coated steels. Welding \& Metal Fabrication. 1996;64:p. 110-4.

[22] Grigor' ev M, Manuilov V, Petrov A, Gromov D. Electrode material for spot welding components. Welding International. 1997;11:909-10. 
[23] Rudolf, Heiko, Juettner, Sven, Graul, Matthias, et al. Method for joining surface materials by using a joining element such as bolts or nuts, comprises welding the joining element with the surface material under mechanical load by resistance heating or inductive heating[P]. : DE102004025492, 2009-08-06.

[24] Manladan S, Yusof F, Ramesh S, Zhang Y, Luo Z, Ling Z. Resistance Element Welding of Magnesium Alloy/austenitic Stainless Steel. IOP Conf Ser Mater Sci Eng2017. p. 012004.

[25] Meschut G, Janzen V, Olfermann T. Innovative and Highly Productive Joining Technologies for Multi-Material Lightweight Car Body Structures. Journal of Materials Engineering \& Performance. 2014;23:1515-23.

[26] Ling Z, Li Y, Luo Z, Feng Y, Wang Z. Resistance Element Welding of 6061 Aluminum Alloy to Uncoated 22MnMoB Boron Steel. Materials and Manufacturing Processes. $2016 ; 31: 2174-80$.

[27] Manladan SM, Yusof F, Ramesh S, Zhang Y, Luo Z, Ling Z. Microstructure and mechanical properties of resistance spot welded in welding-brazing mode and resistance element welded magnesium alloy/austenitic stainless steel joints. Journal of Materials Processing Technology. 2017;250:45-54.

[28] Chen M, Li Q, Zhang P. Experimental investigation of high temperature thermal contact resistance of thin disk samples using infrared camera in vacuum condition. International Journal of Heat \& Mass Transfer. 2020;157:119749.

[29] Bu XZ, Luo Z, Ma YB. The finite element analysis model in modeling the residual stress in the spot welding of aluminum alloys. Welding Technology. 2008:9-12+76.

[30] Li MV, Dong P, Kimchi M. A contact resistance model for resistance spot welding process: theory and implementation. ICAWT. 1997;97:357-69.

[31] Chang BH, Dong D. Finite element simulation of resistance spot welding process of aluminum alloys. Journal of welding. 2004;25:19-22.

[32] Rogeon P, Raoelison R, Carre P, Dechalotte F. A Microscopic Approach to Determine Electrothermal Contact Conditions During Resistance Spot Welding Process. Journal of Heat Transfer. 2008.

[33] ABAQUS user's manual. Dassault Simulia, 2017.

[34] Clark JG. Welding Handbook. New York (NY): Amercian Welding Society, 1942.

[35] Holliday RJ, Parker JD, Williams NTJI, Steelmaking. Prediction of electrode campaign life when spot welding zinc coated steels incorporating electrode tip dressing operations. $1996 ; 23: 157-63$. 
Figures

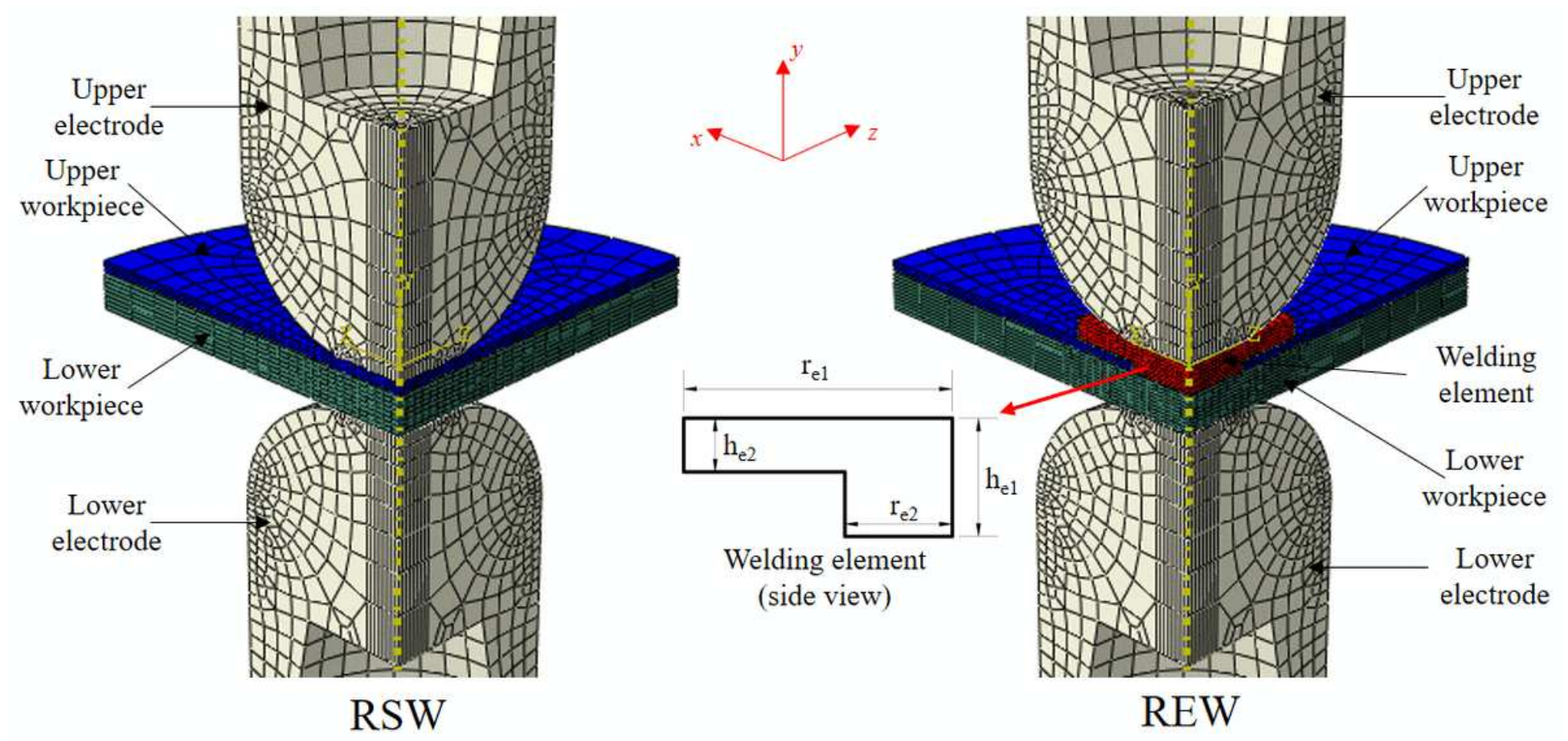

Figure 1

The schematic sketches for the RSW and REW systems. 


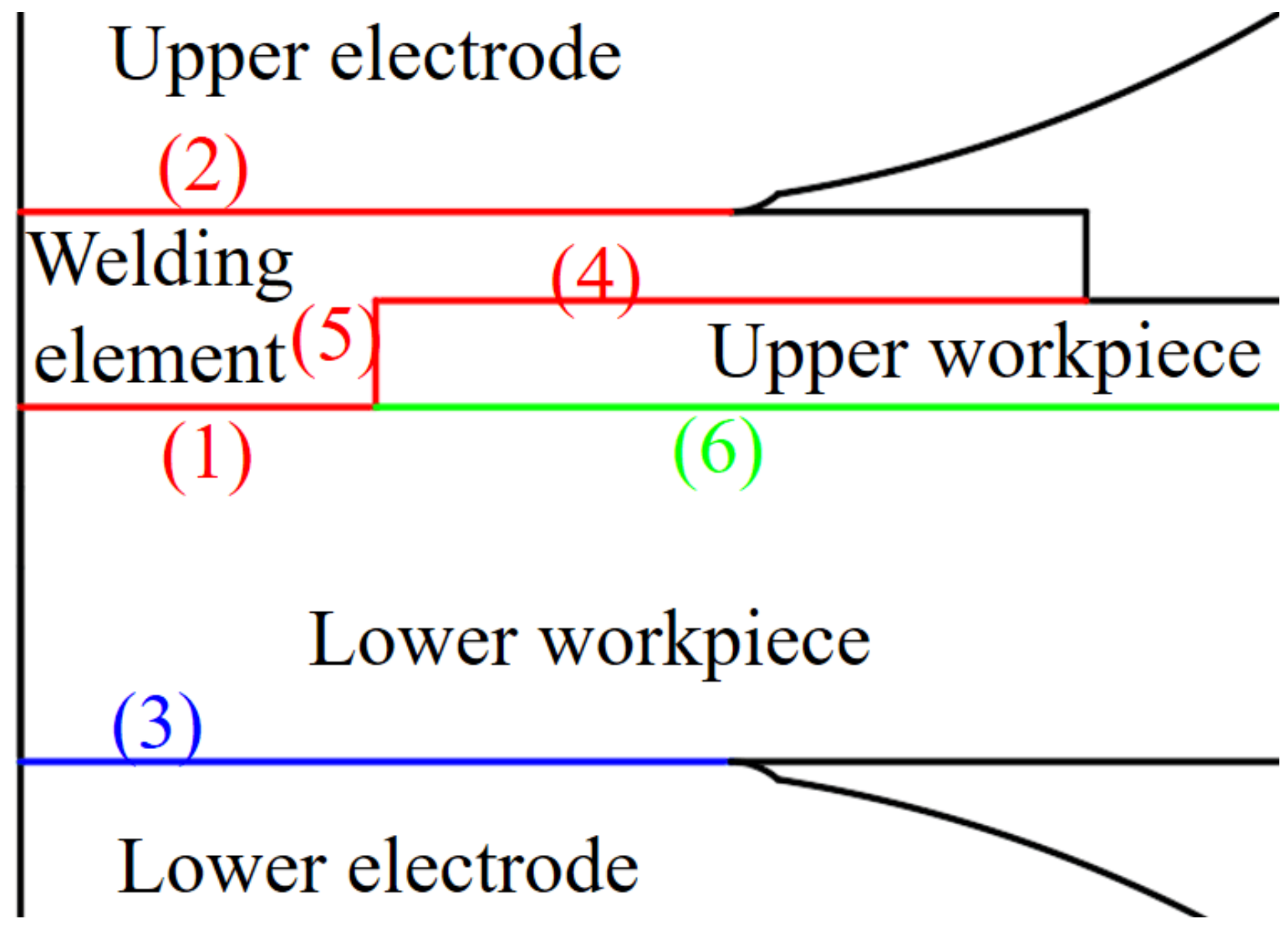

Figure 2

Contact interactions in the REW process.
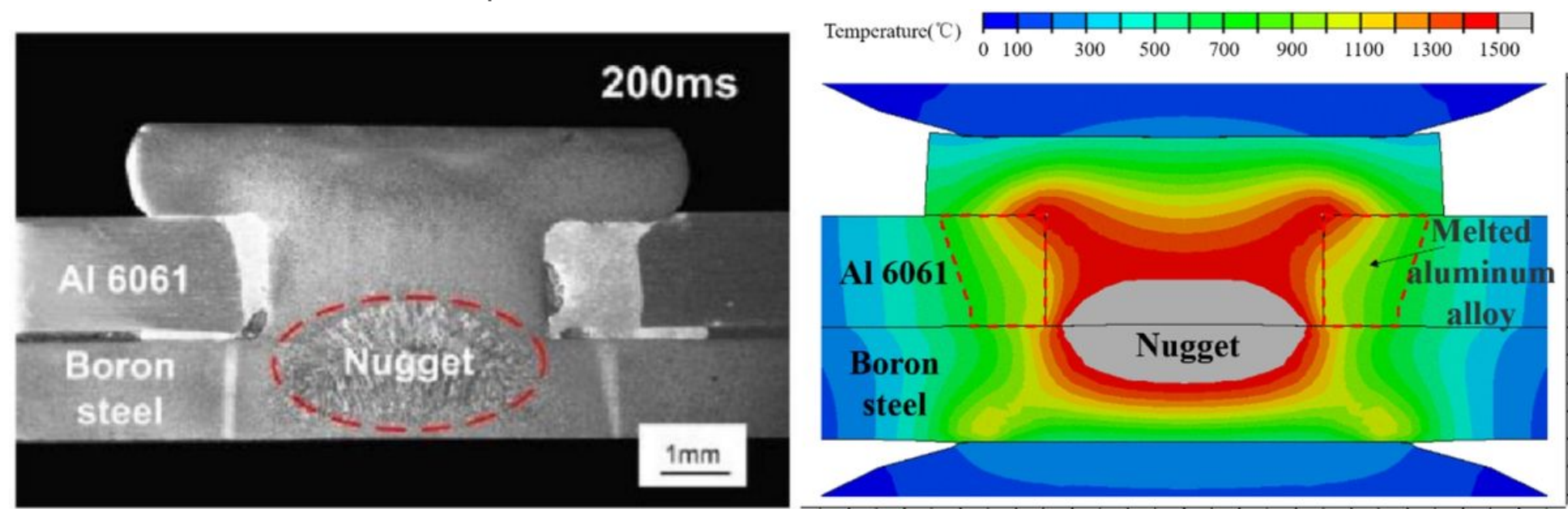

Figure 3

The comparison of 6061 aluminum alloy-boron steel joint with REW: (a) experimental result [26]; (b) simulation result. 

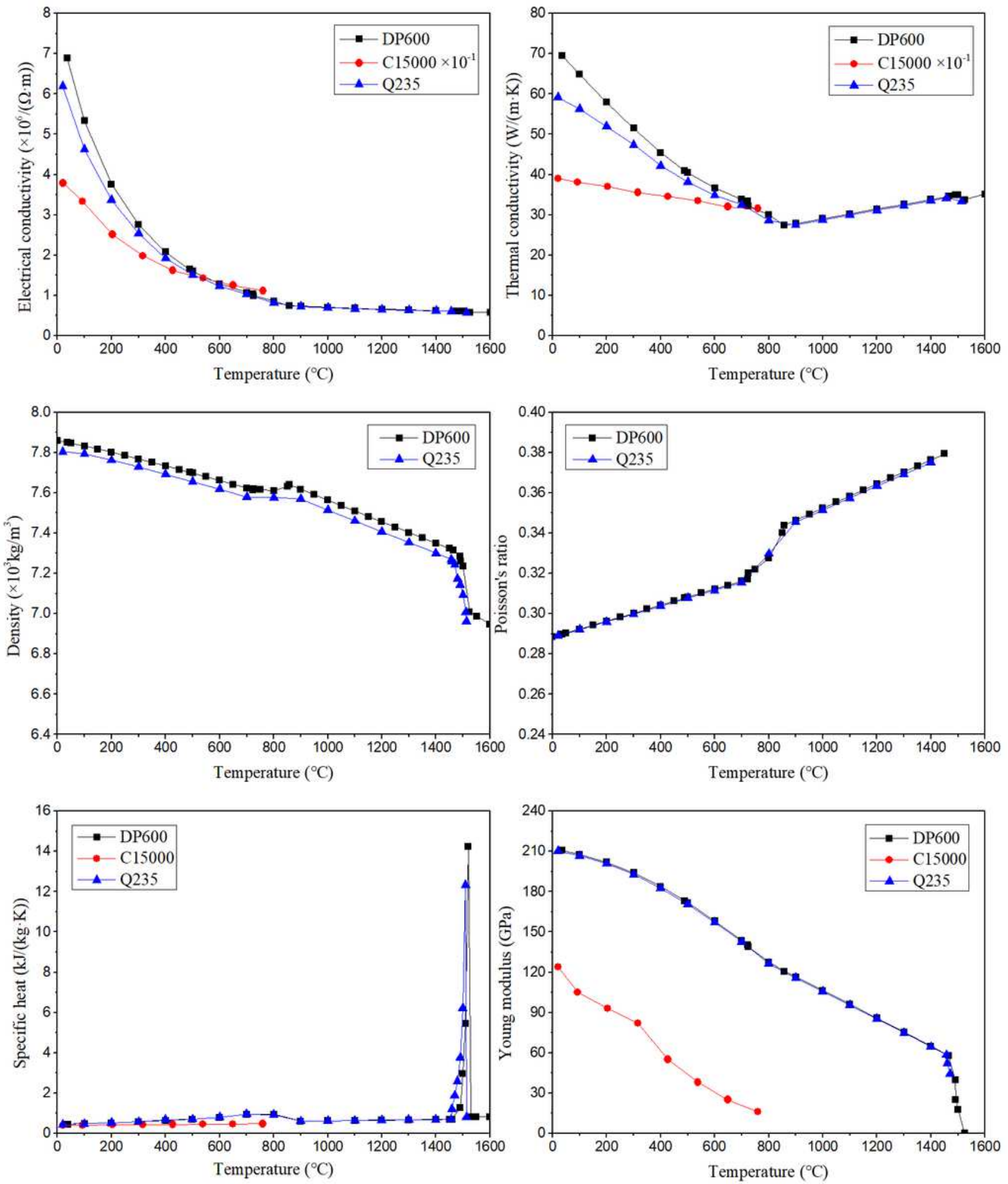

Figure 4

The temperature-dependent material properties of DP600, copper and Q235. 


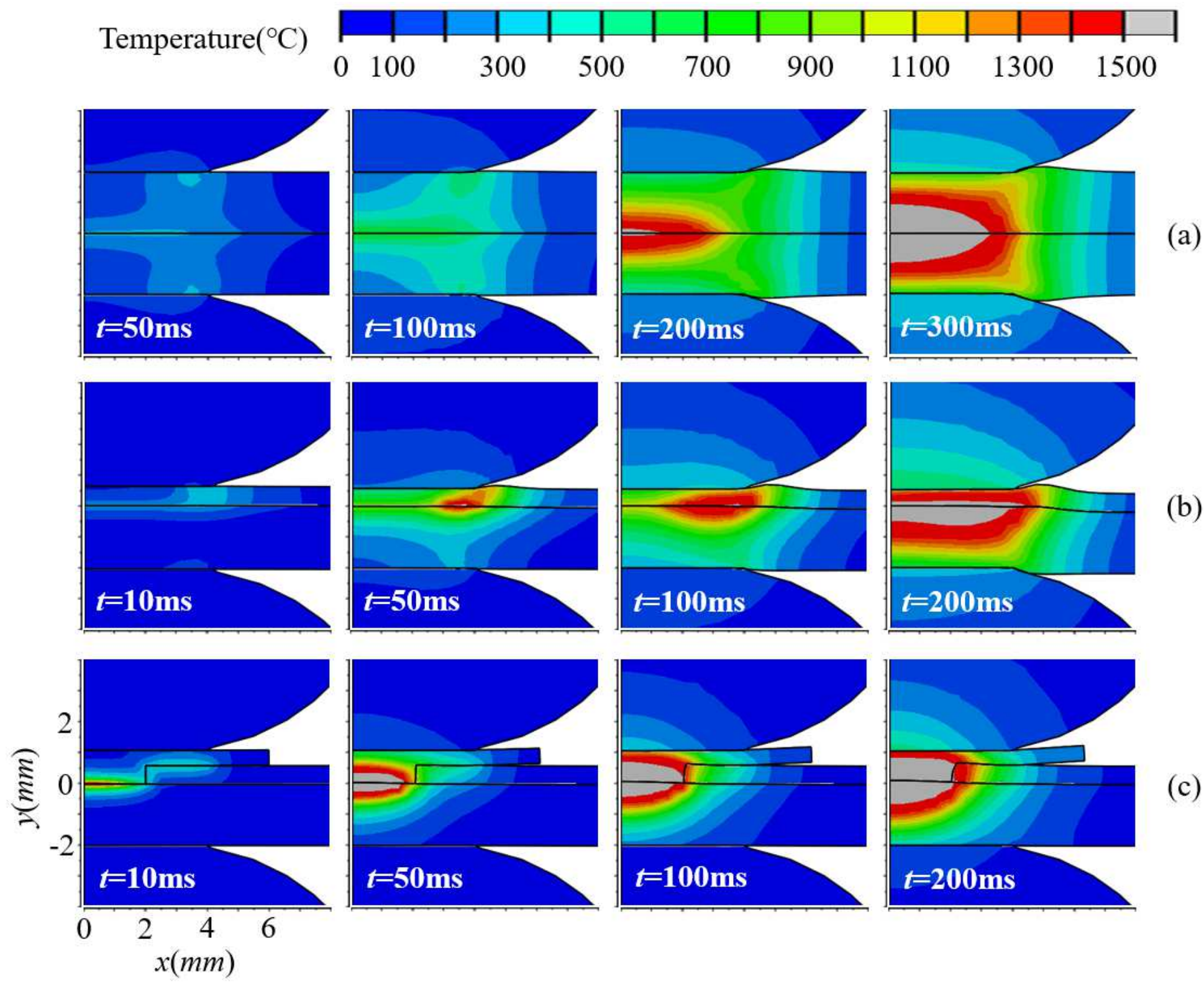

Figure 5

Temperature distributions and nugget growth during RSW/REW of DP600 and Q235with different thickness:(a) RSW 2-mm DP600/2-mm Q235; (b) RSW 0.6-mm DP600/2-mm Q235; (c) REW 0.6mm DP600/2mmQ235. 

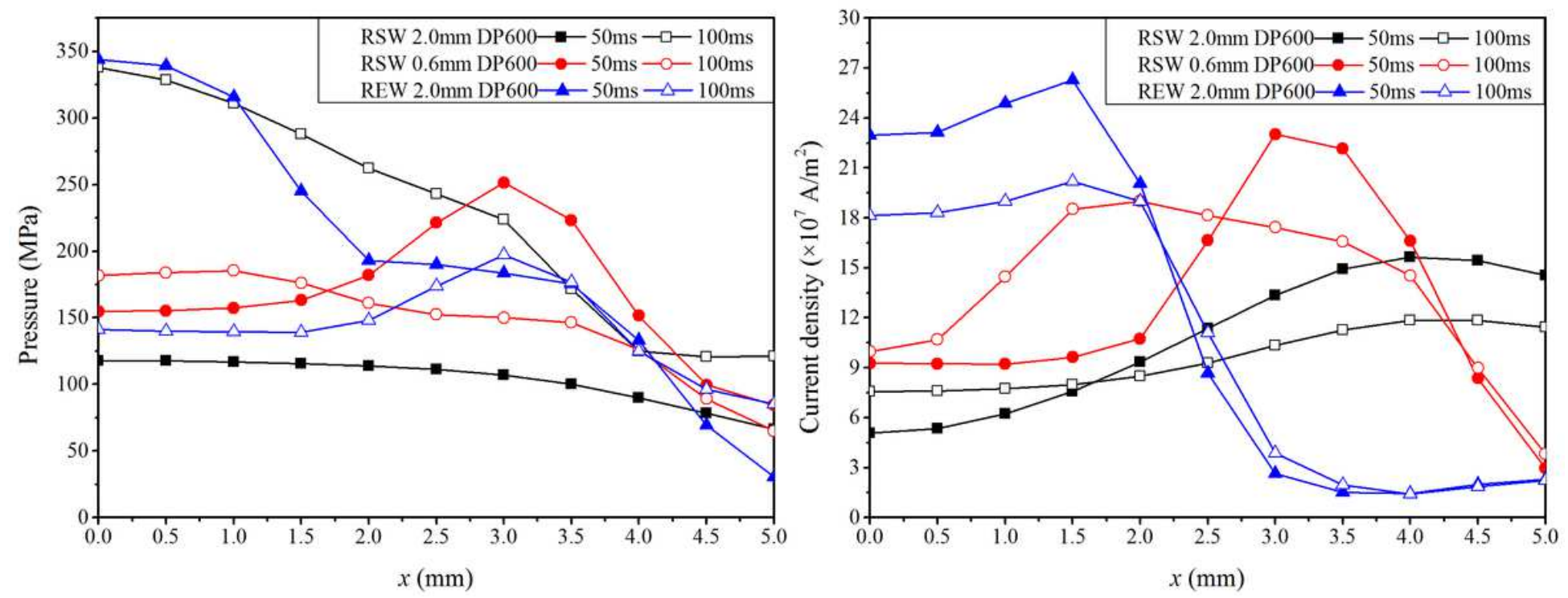

Figure 6

The pressure and current density distributions along the interface between the workpieces for the cases shown in Fig. 5.

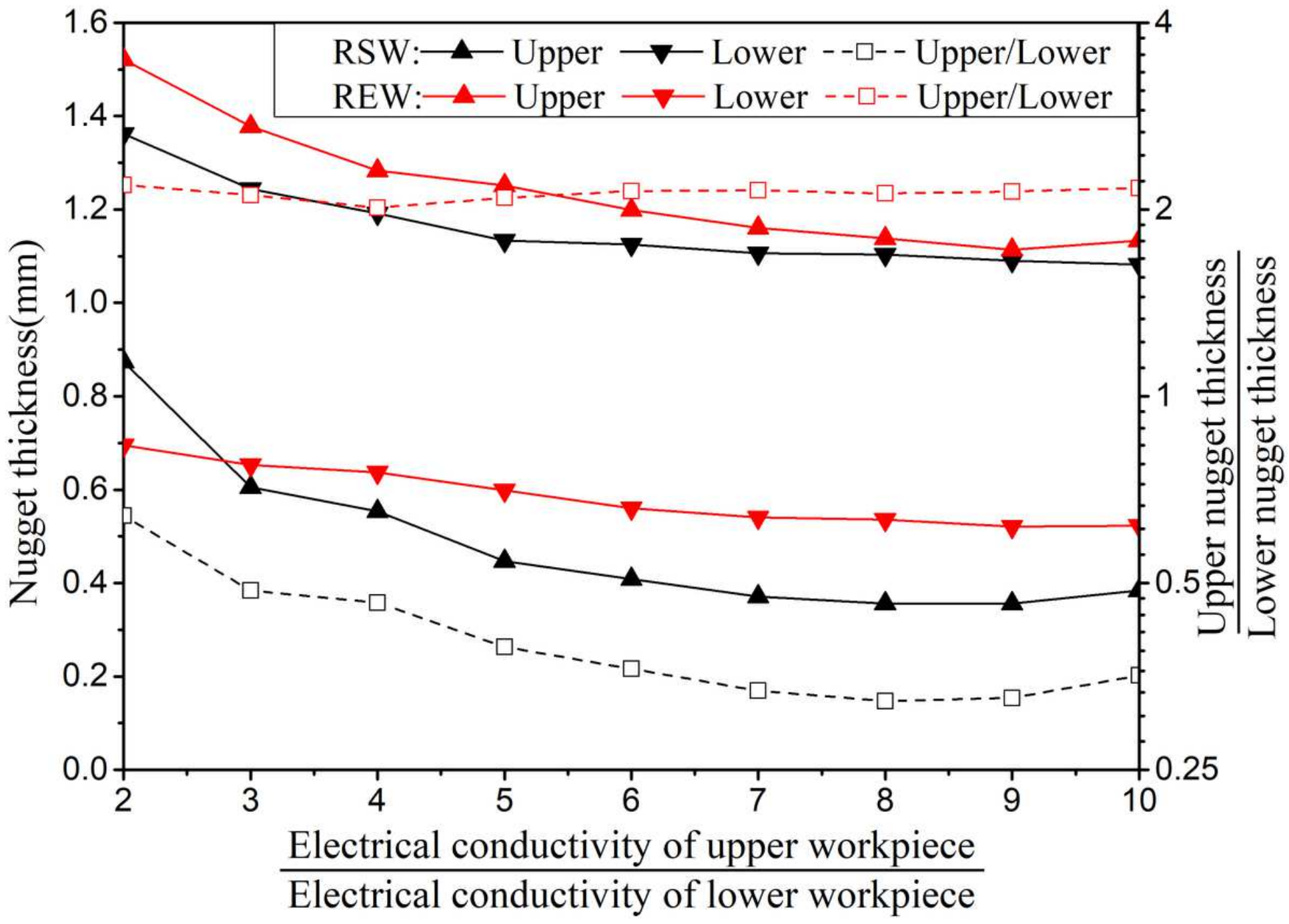


Figure 7

Nugget thickness under different electrical conductivity ratio of the workpieces. (solid line-nugget thickness, dash line-nugget thickness ratio)

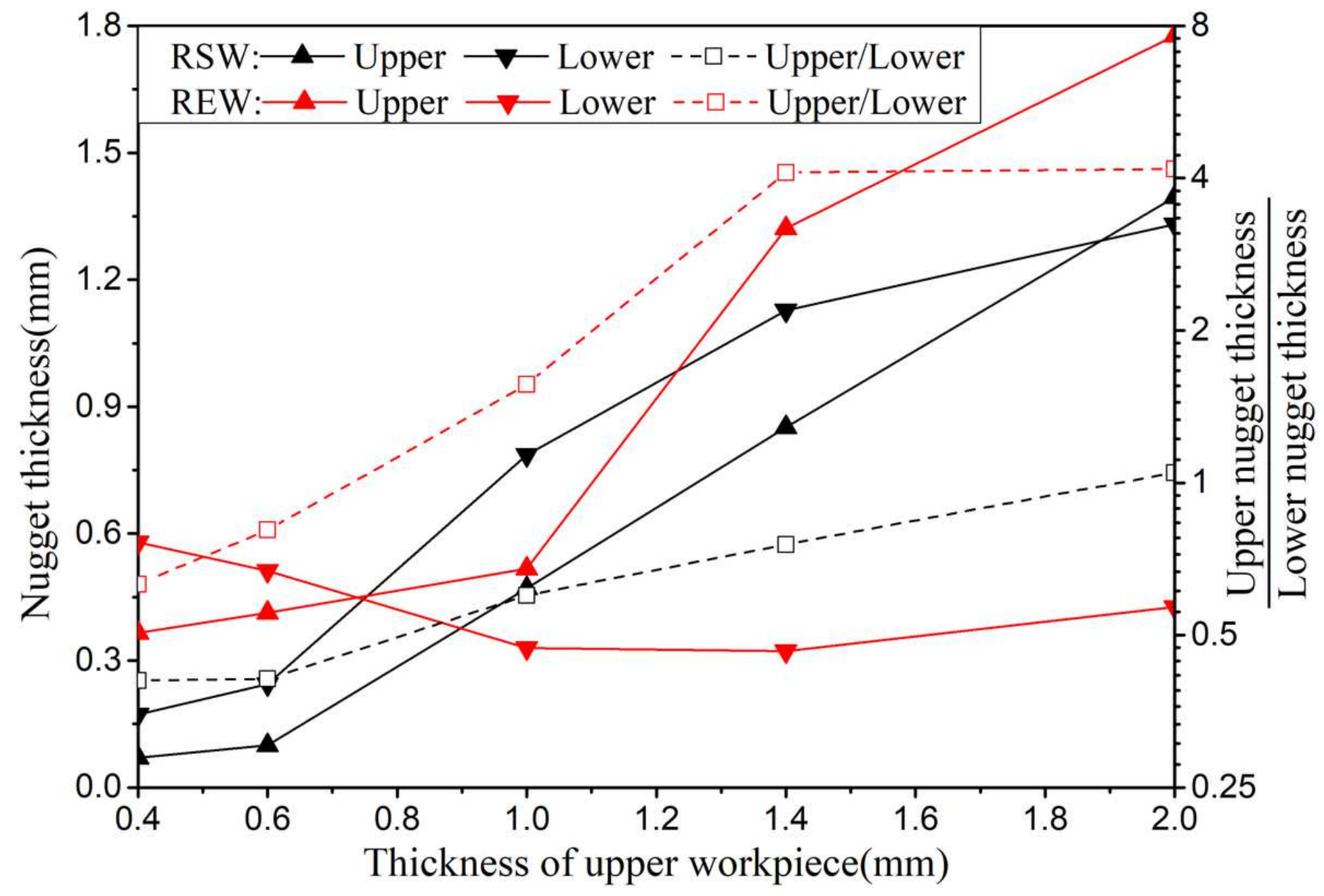

Figure 8

Nugget thickness under different upper workpiece thicknesses (solid line-nugget thickness, dash linenugget thickness ratio) 
Current density

$\left(\times 10^{7} \mathrm{~A} / \mathrm{m}^{2}\right)$
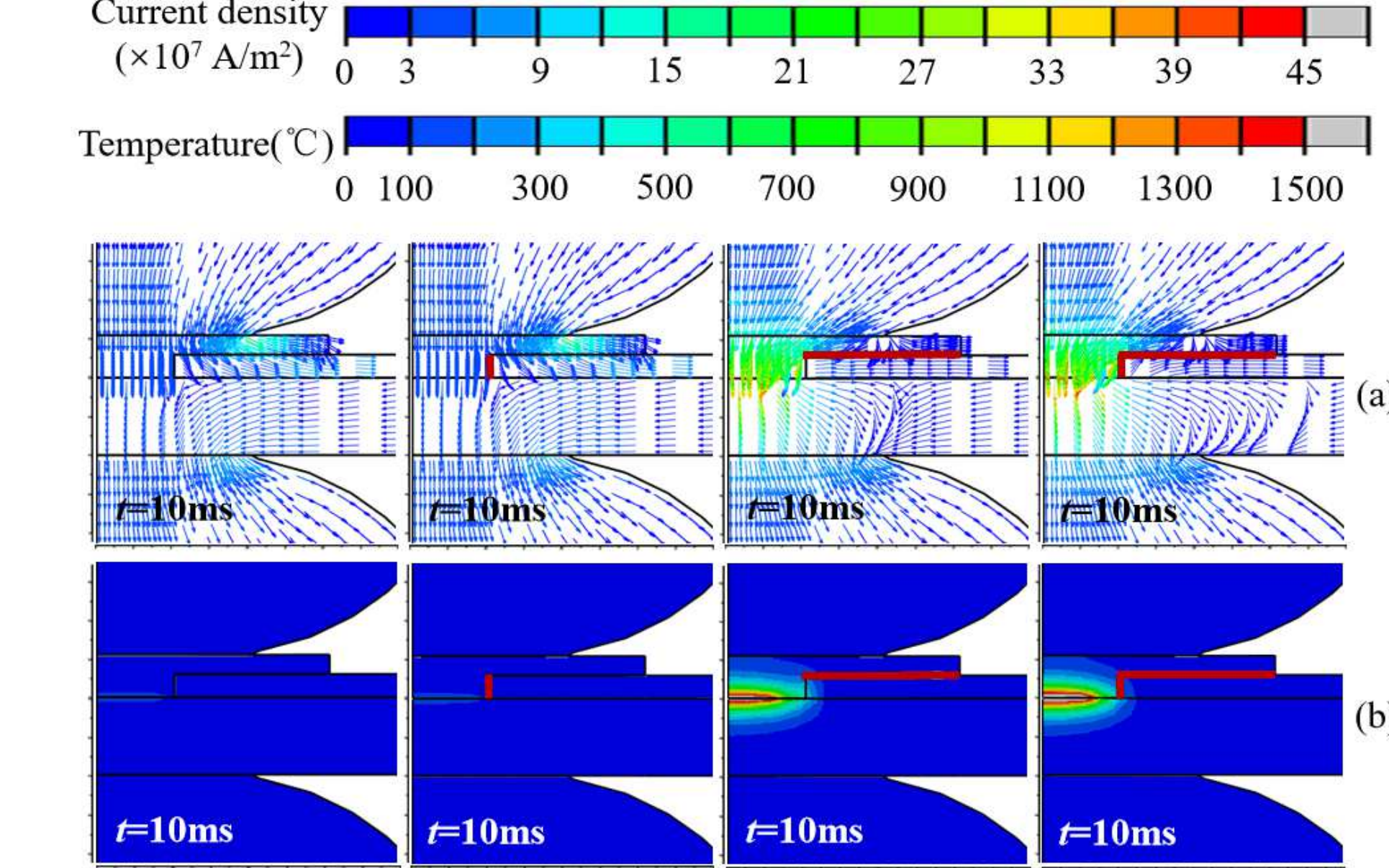

(b)
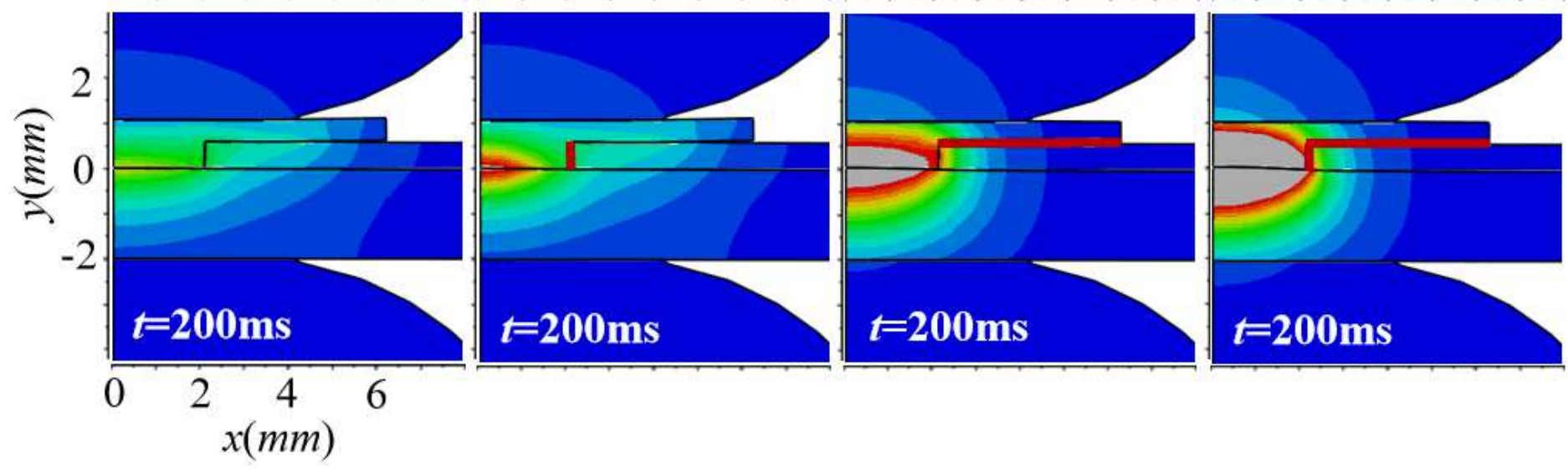

(c)

Figure 9

Distributions of current density and temperature distributions with the nugget dimensions for the REW processes under different insulation conditions: (a) current density at $\mathrm{t}=10 \mathrm{~ms}$, (b) temperature at $\mathrm{t}=10$ $\mathrm{ms}$; (c) temperature at $\mathrm{t}=200 \mathrm{~ms}$. (The red solid line refers to the insulation layer) 


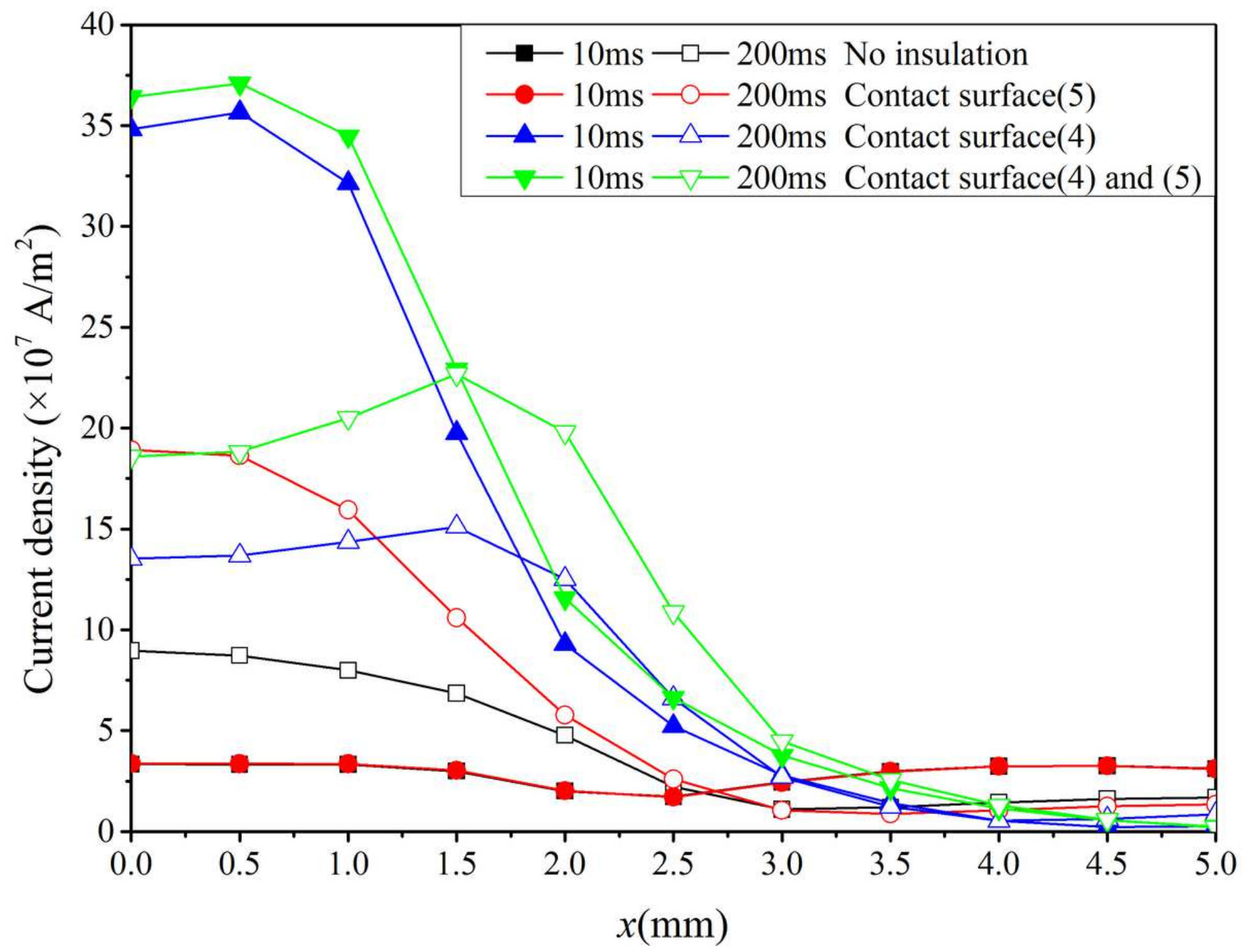

Figure 10

The current density distributions along the interface between the faying interface between the workpieces or element/workpiece. 